\title{
Dual-modality impedimetric immunosensor for early detection of prostate- specific antigen and myoglobin markers based on antibody-molecularly imprinted polymer
}

\author{
Pari Karami ${ }^{\mathrm{a}}$, Hasan Bagheri ${ }^{\mathrm{b}, *}$, Mohammad Johari-Ahar, ${ }^{\mathrm{c}, \mathrm{d}}$, Hosein Khoshsafar ${ }^{\mathrm{a}}$, \\ Fabiana Arduini ${ }^{\mathrm{e}}$, Abbas Afkhami ${ }^{\mathrm{f}}$ \\ ${ }^{a}$ Research and Development Department, Farin Behbood Tashkhis LTD, Tehran, Iran \\ ${ }^{\mathrm{b}}$ Chemical Injuries Research Center, Systems Biology and Poisonings Institute, Baqiyatallah University of Medical Sciences, Tehran, Iran \\ ${ }^{\mathrm{c}}$ Biosensors and Bioelectronics Research Center (BBRC), Ardabil University of Medical Sciences, Ardabil, Iran \\ ${ }^{\mathrm{d}}$ Department of Bioanalytical Sciences and Medicinal Chemistry, School of Pharmacy, Ardabil University of Medical Sciences, Ardabil, Iran \\ ${ }^{\mathrm{e}}$ Department of Chemical Science and Technologies, University of Rome Tor Vergata, Via della Ricerca Scientifica, 00133, Rome, Italy \\ ${ }^{\mathrm{f}}$ Faculty of Chemistry, Bu-Ali Sina University, Hamedan, Iran
}

\section{A R T I C L E I N F O}

\section{Keywords:}

Impedimetric immunosensor

Molecularly imprinted polymer

Prostate-specific antigen

Myoglobin marker

Simultaneous determination

\begin{abstract}
A B S T R A C T
A new dual-modality immunosensor based on molecularly imprinted polymer (MIP) and a nanostructured biosensing layer has fabricated for the simultaneous detection of two important markers including prostatespecific antigen (PSA) and myoglobin (Myo) in human serum and urine samples. In the first step, 3,3'-dithiodipropionic acid di(N-hydroxysuccinimide ester) (DSP) was self-assembled on a gold screen printed electrode (SPE). Then, the target proteins were attached covalently to the DSP-SPE. The imprinted cocktail polymer ((MIP (PSA, Myo)-SPE)) was synthesized at the SPE surface using acrylamide as monomer, N,N'-methylenebisacrylamide as a crosslinker, and PSA and Myo as the templates, respectively. The MIP-SPE was specific for the impedimetric sensing of PSA and Myo. After that, a nanocomposite (NCP) was synthesized based on the decorated magnetite nanoparticles with multi-walled carbon nanotube, graphene oxide and specific antibody for PSA (Ab). Then, NCP incubated with (MIP(PSA, Myo)-SPE. The modified electrodes and synthesized nanoparticles were characterized using electrochemical impedance spectroscopy, dynamic light scattering, surface plasmon resonance and scanning electron microscopy. The limits of detections were found to be $5.4 \mathrm{pg} \mathrm{mL}^{-1}$ and $0.83 \mathrm{ng} \mathrm{mL}^{-1}$ with the linear dynamic ranges of $0.01-100$ and $1-20000 \mathrm{ng} \mathrm{mL}^{-1}$ for PSA and Myo, respectively. The ability of proposed biosensor to detect PSA and Myo simultaneously with high sensitivity and specificity offers a powerful opportunity for the new generation of biosensors. This dual-analyte specific receptors-based device is highly desired for the integration with lab-on-chip kits to measure a wide panel of biomarkers present at ultralow levels during early stages of diseases progress.
\end{abstract}

\section{Introduction}

Prostate-specific antigen (PSA) is a protein that is expressed in high levels by malignant cells of the prostate gland. High content of PSA in men's blood is known as a biomarker for prostate cancer or inflammation, rising age-dependently above 50. Therefore, PSA level is practical for tracing the evolution and response of cancer patients to chemotherapy. PSA test has risen rapidly amongst asymptomatic men worldwide because its determination offers more benefits over a rectal exam or transrectal ultrasonography in the screening of prostate cancers. In contrast to these methods, PSA results are quantitative and reliable, as well as the processes are more acceptable to cancer sufferers [1]. Although PSA is one of the valuable biomarkers in the field of oncology, its blood concentration increases in other prostate disease such as benign prostatic hyperplasia (BPH). There is no specific normal or abnormal level of PSA in the blood, and levels may vary over time in the same man. In the past, PSA levels of $4.0 \mathrm{ng} \mathrm{mL}^{-1}$ and lower was considered as normal values. Therefore, in PSA level above $4.0 \mathrm{ng} \mathrm{mL} \mathrm{m}^{-1}$, a prostate biopsy was often recommend to determine whether prostate cancer was present. However, in some studies prostate cancer have been reported in cases with PSA levels below $4.0 \mathrm{ng} \mathrm{mL}^{-1}$, and many men with higher PSA levels did not have prostate cancer [2].

\footnotetext{
* Corresponding author.

E-mail addresses: h.bagheri82@gmail.com, h.bagheri@bmsu.ac.ir (H. Bagheri).
} 
For myoglobin (Myo), its plasma concentration measured using immunoenzymatic sandwich assay has been reported to be in the normal range of $0-70 \mathrm{ng} \mathrm{mL}^{-1}$. In references, the reported value for normal range of plasma Myo differs slightly [3-5]. However, Myo has been shown to increase above the normal range in prostate cancer patients $[6,7]$.

One strategy to overcome this limitation is to analyze Myo as a biomarker being co-expressed with PSA in prostate cancer. Myo expression is significantly associated with steroid hormone signaling and markers of hypoxia in prostate cancer cases and is of great value as a biomarker in early stage diagnosis [6,7].

Until now, several analytical techniques have been developed for determination of PSA and Myo individually. These include chromatography [8,9], mass spectroscopy [10,11], fluorescence spectroscopy $[12,13]$, nuclear magnetic resonance spectroscopy [14,15], white light reflectance spectroscopy [16,17], capillary electrophoresis [18], chemiluminescence [19], enzyme-linked immunosorbent assays (ELISA) [20,21], electrochemiluminescence [22,23], radioimmunoassay [24,25], time-resolved immunofluorometric assay [26], surface plasmon fluorescence immunoassay [27], bioluminescent immunoassay [28], electrochemical [29], surface-enhanced Raman scattering [24,30] and microcantilever method [31]. Of these methods, biosensors especially electrochemical types can offer some advantages in contrast to the commonly used sensing tools, including simultaneous analysis of biomarkers, capability of miniaturization, lower cost and simplicity of analysis [32-34].

Among electrochemical techniques used in biosensors development, electrochemical impedance spectroscopy (EIS) has attracted attention of analytical scientists due to its capability of monitoring electrode surface changes, allowing the sense of complicated interfacial bio-recognition events. Due to the non-destructive nature of EIS, analysis of binding events at the electrode surface with study of interfacial electron transfer leads to the minimum damage on bio-recognition elements and bio-analytes used in biosensor development, and more reproducible results can be recorded from the developed biosensor [35].

Screen-printed electrodes (SPE) are innovative strips designed for working with microvolumes of samples. In this type of electrode, working, reference and counter electrodes are printed on a polymeric substrate with a reduced sizes in contrast to conventional electrodes, showing some advantages such as lower cost, disposability and flexibility of analysis [36,37].

From bio-recognition elements used such as antibody, aptamer, nucleic acid hybridizing stands, molecularly imprinted polymers (MIPs), as synthetic receptors, is encouraging an alternative to biomolecules in the construction of biosensors. Such materials are synthesized in the presence of functional monomers, cross-linker and analyte (template) by covalent and noncovalent mechanisms [38,39]. The advantages of MIPs compared to biological counterparts, are their resistance to high temperatures and acidic or basic conditions, ease of construction, low cost and reusability [40,41].

In this work, we report a novel, low cost, MIP-based biosensor to detect PSA and Myo in serum and urine samples simultaneously. The sensing strategy was designed by the combination of a molecularly imprinted technique and immunoassay method on the disposable SPE surface. MIP is prepared with methyl acrylate as monomer and ethylene glycol dimethacrylate as a crosslinker in the presence of PSA and Myo as templates. Nanocomposite was synthesized based on the $\mathrm{Fe}_{3} \mathrm{O}_{4}$ nanoparticles decorated with multi-walled carbon nanotube (MWCNT), graphene oxide (GO), MWCNT-GO and specific antibody for PSA (Ab). The determination process of analytes includes two steps: (1) Imprinted sensor was exposed to the solutions of PSA and Myo. Then recognition signal of PSA and Myo on the MIP sensor was detected using electrochemical impedance spectroscopy (EIS) technique. (2) In the following step, the MIP was exposed to synthesized nanocomposite (NCP). After an immune reaction between MIPs, PSA and the NCP, the immunocomplex was formed, and the $R_{c t}$ values were measured. The signal in the first step is proportional to the PSA and Myo concentration and the signal in the second step is proportional to the PSA concentration. Furthermore, the difference in electrical resistance of twostep was proportional to the amount of Myo binding. All fabrication steps of the engineered biosensor are schematically illustrated in Scheme 1. The developed impedimetric sensor showed a high recognition capability toward PSA and Myo as well as a wide linear range and a low detection limit under optimized conditions.

\section{Materials and methods}

\subsection{Chemicals}

Potassium ferrocyanide $\left(\mathrm{K}_{4}\left[\mathrm{Fe}(\mathrm{CN})_{6}\right]\right)$, Potassium ferricyanide $\left(\mathrm{K}_{3}\left[\mathrm{Fe}(\mathrm{CN})_{6}\right]\right)$, Potassium hydrogen phosphate $\left(\mathrm{K}_{2} \mathrm{HPO}_{4}\right)$ and Potassium dihydrogen phosphate $\left(\mathrm{KH}_{2} \mathrm{PO}_{4}\right)$ obtained from Merck. Ammonium persulphate, $\mathrm{N}, \mathrm{N}^{\prime}$-methylenebisacrylamide (NNMBA) and acrylamide (AAM) purchased from Fluka. Sodium chloride, 3,3'-dithiodipropionic acid di(N-hydroxysuccinimide ester) (DSP), potassium chloride, 3-(Trimethoxysilyl)-propylamine (APTS), Myo ELISA kit, hydroquinone, oxalic acid (OxA) and Myo obtained from Sigma. Monoclonal anti-PSA antibody and PSA obtained from HyTest. PSA ELISA kit purchased from Abcam. Carboxylate multi-walled carbon nanotube (MWCNT), magnetite $\left(\mathrm{Fe}_{3} \mathrm{O}_{4}\right)$, graphene oxide (GO) purchased from Us-Nano. All solutions prepared in deionized water.

\subsection{Preparation of NCP (Ab-GO-MWCNT- $\left.\mathrm{Fe}_{3} \mathrm{O}_{4}\right)$}

The aqueous solution containing $\mathrm{Fe}_{3} \mathrm{O}_{4}\left(0.5 \mathrm{mg} \mathrm{mL}^{-1}\right)$ and acetic acid $(0.01 \% \mathrm{v} / \mathrm{v})$ were prepared and APTS solution $(0.5 \% \mathrm{v} / \mathrm{v})$ was added to this solution. The mixture stirred for $72 \mathrm{~h}$ which lead to particles precipitation. The resulting modified APTS-Fe3O4 particles were collected using a magnet and then were washed three times with deionized water. The washed precipitate stored in deionized water.

To activate carboxylic functional groups of MWCNT and GO, the borate buffer solution ( $\mathrm{pH}$ 9) containing $20 \mathrm{mg} \mathrm{mL}^{-1} \mathrm{EDC}$ and $10 \mathrm{mg} \mathrm{mL}^{-1}$ NHS was added to solution of $1 \mathrm{mg} \mathrm{mL}^{-1}$ MWCNT and GO under stirring and incubated for $30 \mathrm{~min}$ at room temperature.

To covalently attach APTS- $\mathrm{Fe}_{3} \mathrm{O}_{4}$ nanoparticles with MWCNT and $\mathrm{GO}$, the activated nanoparticles incubated with APTS- $\mathrm{Fe}_{3} \mathrm{O}_{4}$ $\left(0.2 \mathrm{mg} \mathrm{mL}^{-1}\right)$ at room temperature and dark overnight. The prepared MWCNT-GO- $\mathrm{Fe}_{3} \mathrm{O}_{4}$ particles were collected using a magnet and then were washed three times with deionized water to remove excess free and non-attached GOs and MWCNTs. The product stored in deionized water.

To covalently attach MWCNT-GO- $\mathrm{Fe}_{3} \mathrm{O}_{4}$ nanoparticles with Ab, MWCNT-GO- $\mathrm{Fe}_{3} \mathrm{O}_{4}$ were dispersed in $\mathrm{Ab}$ solution at $8{ }^{\circ} \mathrm{C}$ and dark under shaking $(60 \mathrm{rpm})$ for $24 \mathrm{~h}$. The prepared Ab-MWCNT-GO- $\mathrm{Fe}_{3} \mathrm{O}_{4}$ nanoparticles transferred to PBS buffer solution $\left(10 \mathrm{mmol} \mathrm{L}^{-1}\right)$ containing sodium azide $(0.1 \%)$ at $4{ }^{\circ} \mathrm{C}$ for following applications.

\subsection{Architecture of MIP-SPE}

All construction steps of developed biosensor are schematically demonstrated in Scheme 1. DSP monolayer was self-assembled on SPE by soaking electrodes in the solution of DSP $\left(10 \mathrm{mmol} \mathrm{L}^{-1}\right)$ under stirring at room temperature for $60 \mathrm{~h}$. DSP-SPE were investigated using ESI, and charge transfer resistance $\left(\mathrm{R}_{\mathrm{ct}}\right)$ values were calculated. The obtained DSP-SPE was washed with deionized water and then dried via nitrogen stream.

To form covalent bond on the surface of electrode, DSP-SPE was reacted with Myo and PSA (ratio: 1:1) and incubated for $24 \mathrm{~h}$. Then 


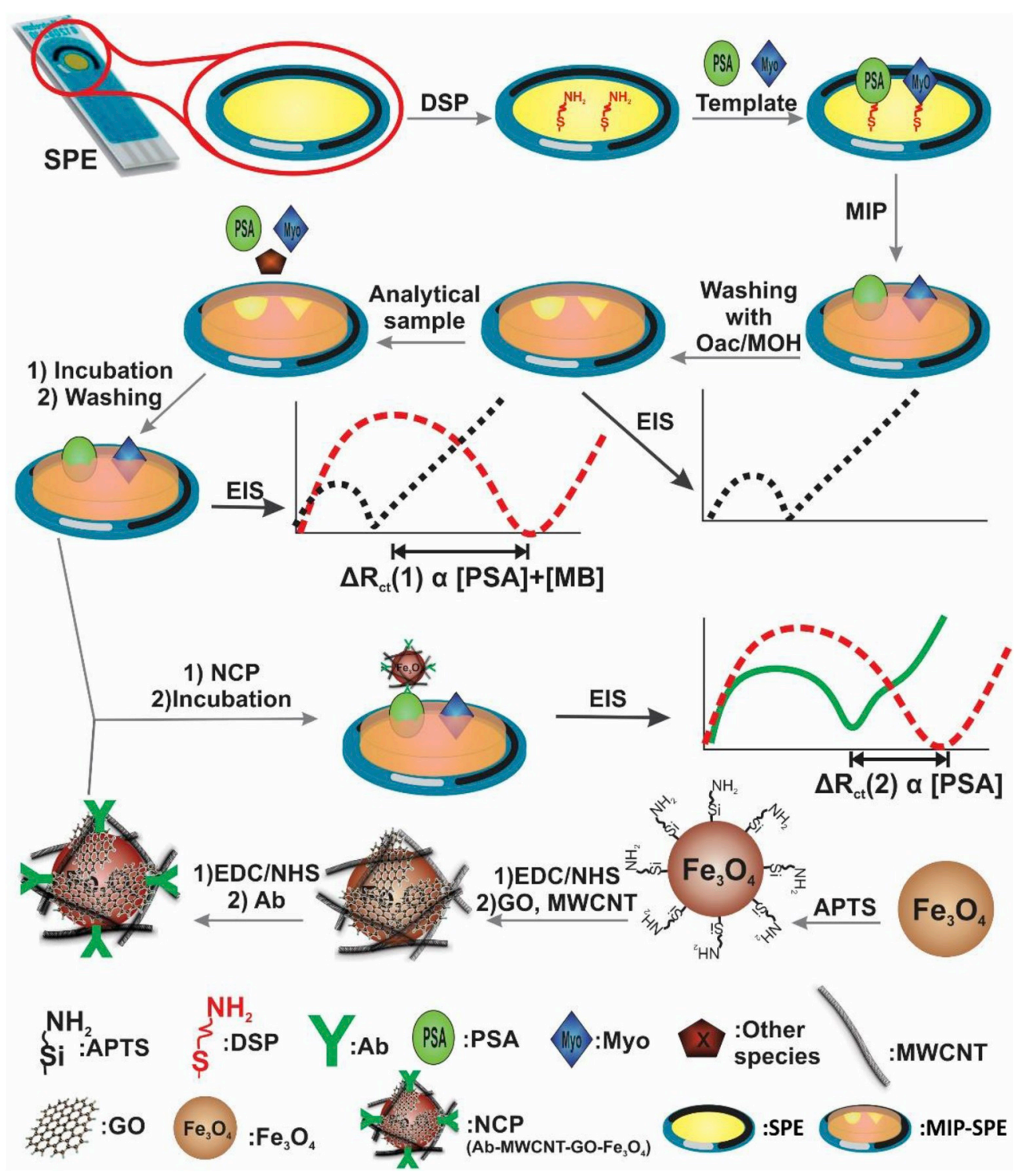

Scheme 1. Illuatration of the assembly and performance of the developed sensor and immunosensor.

DSP-SPE surface blocking was carried out by soaking it in $10 \% \mathrm{w} \mathrm{v}^{-1}$ solution of AAM monomer for $24 \mathrm{~h}$. In the next step, ammonium persulphate (APS) was used to polymerize AAM and NNMBA to form MIP on the SPE (DSP(PSA, Myo)-SPE) [31]. The imprinting process was performed using $10 \mathrm{mmol} \mathrm{L}^{-1}$ AAM solution $(25 \mu \mathrm{L})$ and $70 \mathrm{mmol} \mathrm{L}^{-1}$ NNMBA $(25 \mu \mathrm{L})$ in the presence of DSP-SPE. Then $10 \mu \mathrm{L}$ PBS (pH 7.4) solution containing $60 \mathrm{mmol} \mathrm{L}^{-1}$ of APS was added. The hydroquinone in ethanol $(1 \% \mathrm{w} / \mathrm{v})$ was used as stop solution. The Myo and PSA (template Molecules) were washed from MIP(PSA, Myo)-SPE by incubation with OxA $\left(1 \mathrm{~mol} \mathrm{~L}^{-1}\right)$ solution for $12 \mathrm{~h}$. OxA was able to break peptide bonds, allowing a successful removal of the template molecules from the imprinted layer [42]. The EIS was used to monitor whole process.

\subsection{EIS analysis}

All electrochemical experiments and EIS investigations were carried out using a CompactStat h 1030 Electrochemical Analyzer (Ivium Technologies). The Single-use screen-printed gold electrodes were purchase from Metrohm Co. (Schiedam, Netherland, code: 6.1208.210) comprising a working electrode (gold, diameter of $4 \mathrm{~mm}$ ) and carbon-based counter electrode and silver pseudo-reference electrode. The connection of SPE to the Ivium is provided by a specific homemade connector. The investigations were carried at ambient temperature by drop-casting a solution $(50 \mu \mathrm{L})$ onto the working electrode surface. All EIS experiments, which were performed within a frequency range of $0.1 \mathrm{~Hz}-100 \mathrm{kHz}$ at the formal potential of redox couple $\mathrm{Fe}(\mathrm{CN})_{6}{ }^{4-/ 3-}(0.17 \mathrm{~V})$, were recorded in the solution containing $5 \mathrm{mmol} \mathrm{L}^{-1} \mathrm{~K}_{3}\left[\mathrm{Fe}(\mathrm{CN})_{6}\right] / \mathrm{K}_{4}\left[\mathrm{Fe}(\mathrm{CN})_{6}\right](1: 1)$ and PBS $\left(0.1 \mathrm{~mol} \mathrm{~L}^{-1}, \mathrm{pH} 7\right)$. The impedance data were represented in the form of a complex plot (Nyquist plot), and the fitting program of CompactStat $h 1030$ Electrochemical Analyzer was used to analyze the impedance spectra with an appropriate equivalent electrical circuit.

\subsection{Dynamic light scattering (DLS) analysis}

To determine the dynamic diameterof prepared nanoparticles, DLS investigations were performed using Nanotrac Wave ${ }^{\mathrm{TM}}$ (Microtrac). Data analysis was perform by fitting the data to a polydispersed model using 

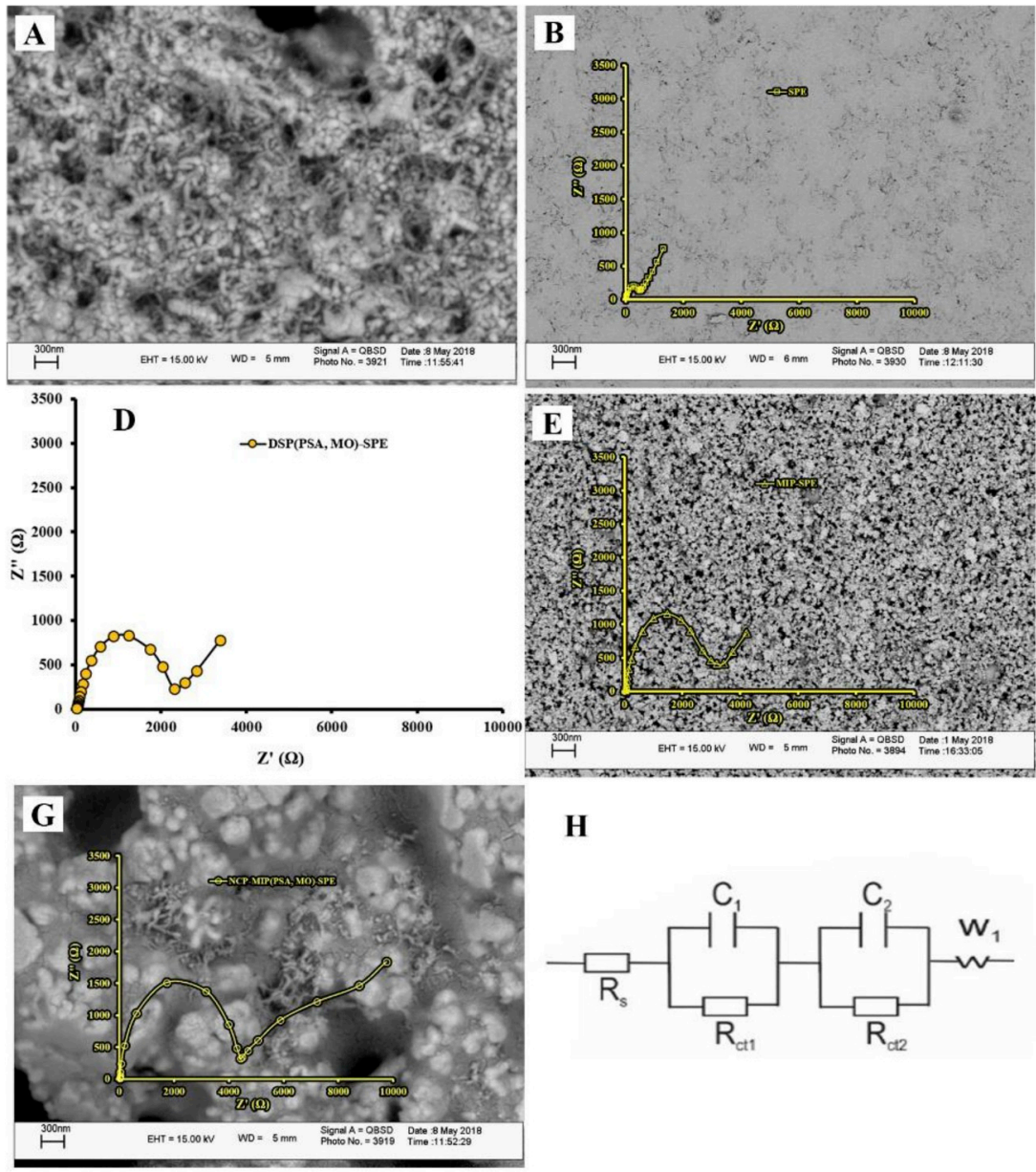

$\mathbf{H}$

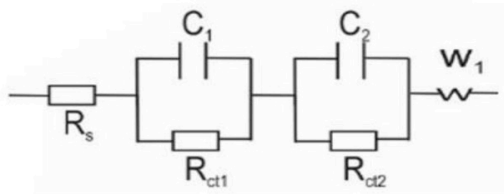

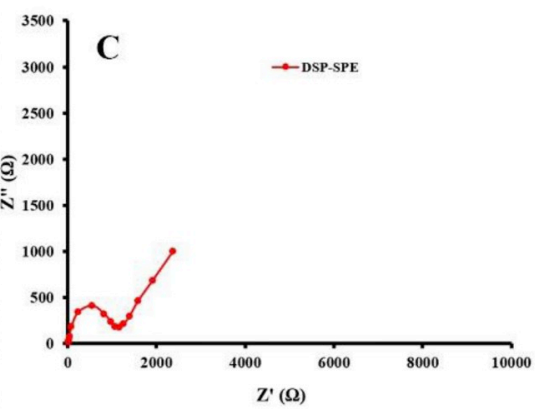

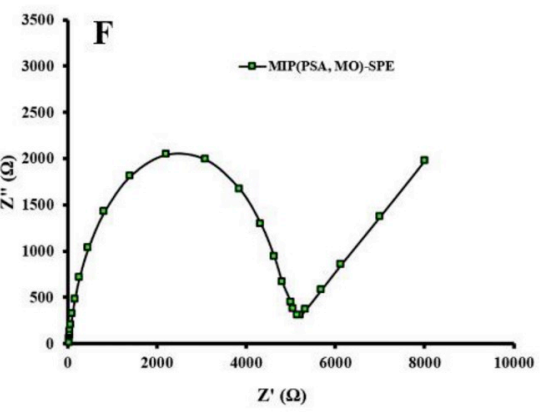

I

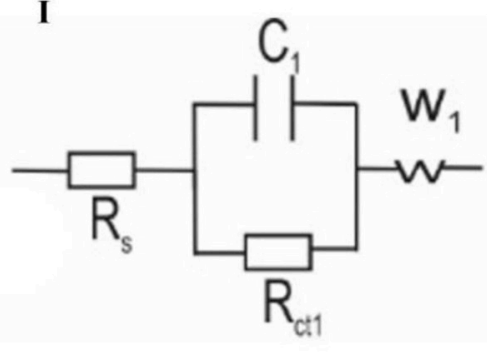

Fig. 1. (A to G) EIS and SEM analysis for step by step fabrication of impedimetric sensor (NCP, bare SPE, DSP-SPE, DSP(PSA, Myo)-SPE, MIP-SPE, MIP(PSA, Myo)SPE, NCP-MIP(PSA, Myo)-SPE respectively). Equivalent circuits obtained by fitting Nyquist plots of (H) the NCP-MIP(PSA, Myo)-SPE and (I) other modified electrodes.

the Dynamics software version 5.26.

\subsection{Scanning electron microscopy (SEM) analysis}

SEM analysis was carried out to detect morphology of NCP, SPE, MIP-SPE and NCP-MIP-SPE. Scanning electron microscope model MIRA3 FEG-SEM Tescan was used and samples were gold plated before to analysis to avoid charge accumulation.

\subsection{Surface plasmon resonance (SPR) analysis}

SPR analysis were carried out using a Biacore T100 system. To rinse the gold surface, the chip was first soaked in piranha solution $(10 \mathrm{~mL}$, $70 \% \mathrm{H}_{2} \mathrm{SO}_{4}: 30 \% \mathrm{H}_{2} \mathrm{O}_{2}$ ) for 5 min followed by washing with amounts of ethanol and deionized water. Clean chip instead of working electrode connected to electrochemical analyzer and the polymerization process was performed the same as see section 2-3. The SPR investigations were started by injecting the running buffer $\left(10 \mathrm{mmol} \mathrm{L}^{-1}\right.$ Tris- $\mathrm{HCl}$, $1 \mathrm{mmol} \mathrm{L}^{-1}$ EDTA, and $1 \mathrm{~mol} \mathrm{~L}^{-1} \mathrm{NaCl}$; $\mathrm{pH}$ 7.4) into the system (rate: $30 \mu \mathrm{Lmin}^{-1}$ ) until the baseline became stable. One channel was unmodified MIP-Au chip to provide an additional reference surface; the other channel on the MIP-Au chip was incubate with PSA (MIP(PSA)-Au chip) or Myo (MIP(Myo)-Au chip) ( $30 \mu \mathrm{L}$ of 5 or $100 \mathrm{ng} \mathrm{mL}^{-1}$ respectively) in $1 \mathrm{~mol} \mathrm{~L}^{-1} \mathrm{PBS}(\mathrm{pH} 7$ ) at a rate of $30 \mu \mathrm{L}$ min-1. Subsequently, $5 \mathrm{mmol} \mathrm{L}^{-1}$ Tris-HCl buffer containing $10 \mathrm{mmol} \mathrm{L}^{-1} \mathrm{NaCl}(\mathrm{pH} 7.4)$ was introduced to wash out the free, unbound PSA or Myo. Then one channel was unmodified MIP(PSA)-Au chip to provide an additional reference surface; the other channel on the MIP(PSA)-Au chip was modified with NCP solution (NCP-MIP(PSA)-Au chip) at a rate of $30 \mu \mathrm{Lmin}^{-1}$. Subsequently, $5 \mathrm{mmol} \mathrm{L}^{-1}$ Tris-HCl buffer containing10 $\mathrm{mmol} \mathrm{L}^{-1} \mathrm{NaCl}$ (pH 7.4) was introduced to wash out the free, unbound NCP. Finally, the SPR data were evaluated using Biacore T100 evaluation software (v. 1.1.1) to calculate the values of the kinetic parameters $\mathrm{K}_{\mathrm{a}}$ and $\mathrm{K}_{\mathrm{d}}$.

\subsection{The amount of $A b$ immobilized on NCP}

The amount of Ab immobilized on MWCNT-GO- $\mathrm{Fe}_{3} \mathrm{O}_{4}\left(6.2 \mathrm{ng} \mathrm{g}^{-1}\right.$ of $\mathrm{NCP})$ was measured indirectly using Pierce BCA protein assay kit.

\subsection{Assessment of biosensor performance}

To evaluate performance of the developed biosensor MIP-SPE was immersed into solutions of PSA and Myo for $60 \mathrm{~min}$ at ambient temperature and then rinsed with buffer solution to form MIP(PSA, Myo)SPE (Scheme 1). The $R_{\text {ct }}$ of MIP-SPE and MIP(PSA, Myo)-SPE were measured using EIS and the difference in the $R_{c t}$ values between $\left(\Delta \mathrm{R}_{\mathrm{ct}}(1)\right)$ MIP-SPE and MIP(PSA, Myo)-SPE were indirectly indicative of sum of PSA and Myo concentrations.

Next, MIP(PSA, Myo)-SPE were incubated with NCP for $90 \mathrm{~min}$ at $37^{\circ} \mathrm{C}$, and after being washed with buffer solution. EIS was carried out to measure $R_{c t}$ values. Difference in the $R_{c t}$ values of MIP(PSA, Myo)- 

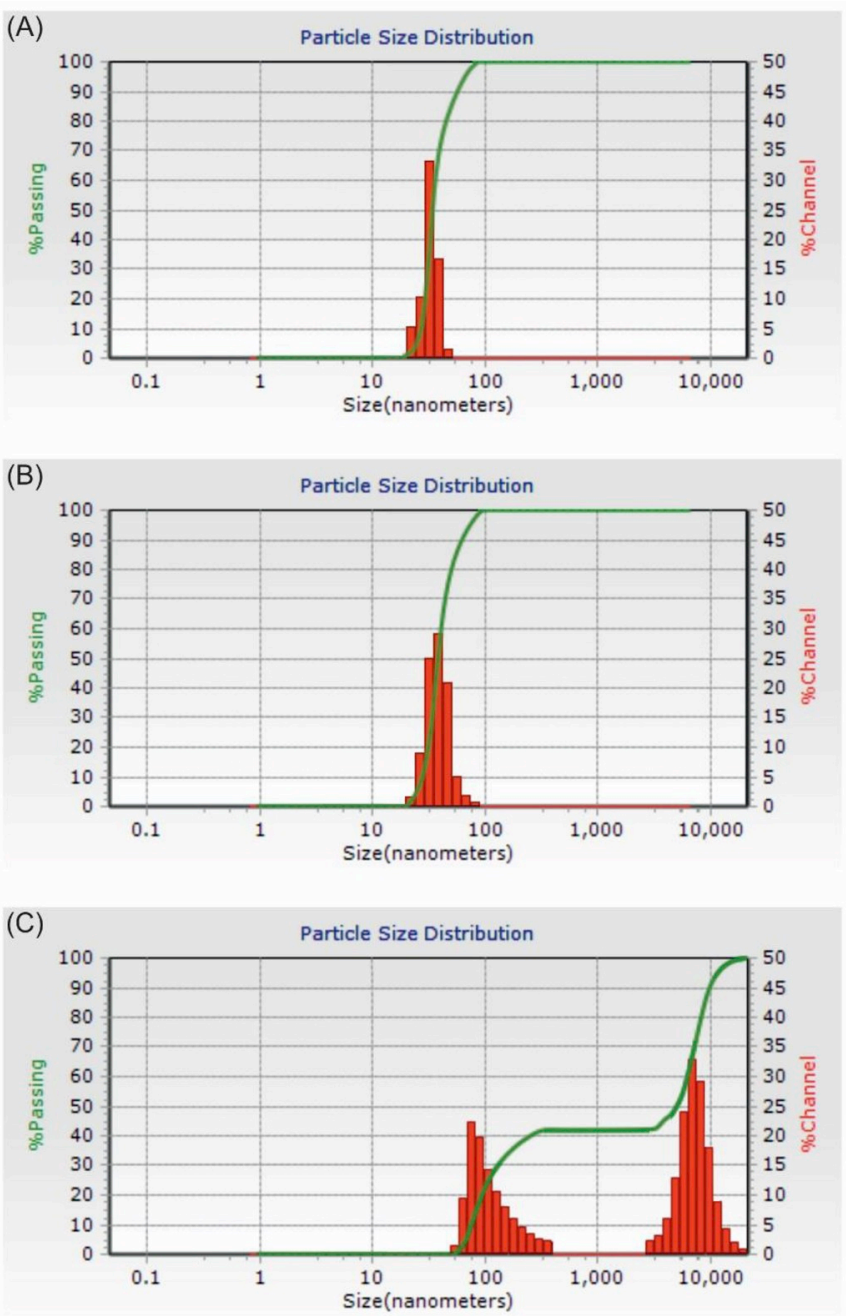

Fig. 2. DLS characterization of (A) $\mathrm{Fe}_{3} \mathrm{O}_{4}$, (B) APTS- $\mathrm{Fe}_{3} \mathrm{O}_{4}$ and (C) NCP.

SPE and NCP-MIP(PSA, Myo)-SPE $\left(\Delta \mathrm{R}_{\mathrm{ct}}(2)\right)$ were indirectly indicative of PSA concentrations. Scheme 1 demonstrates the assembly and performance of the proposed biosensor.

\section{Results and discussion}

\subsection{Characterization}

\subsubsection{EIS analysis}

EIS is a very robust method that is broadly applied to investigate the binding of molecules upon a sensor surface. Fig. 1 depicts the Nyquist plots of bare SPE (curve B), DSP-SPE (curve C), DSP (PSA, Myo)-SPE (curve D), MIP-SPE (curve E), MIP(PSA, Myo)-SPE (curve F), NCP-MIP (PSA, Myo)-SPE (curve G). In the Nyquist plot, semicircles diameter illustrates a faradaic resistance displaying electron transfer resistance $\left(\mathrm{R}_{\mathrm{ct}}\right)$. Furthermore, at low frequencies, Warburg impedance can be seen. When DSP was self-assembled on the SPE, $R_{c t}$ value increased significantly (curve B), revealing the high insulating capability of DSP. Also, the $\mathrm{R}_{\mathrm{ct}}$ value raised slightly after the attachment of PSA and Myo with DSP-SPE in the presence of PSA and Myo, slightly raised (curve C) representing the increased resistance of the double layer. As can be seen in curve e, when MIP was formed on the surface of the electrode, leads to an increase in $R_{\mathrm{ct}}$ value. After template removal from the imprinted polymer using OxA, the $\mathrm{R}_{\mathrm{ct}}$ value of MIP-SPE was notably declined (curve D). It seems that the removal of analytes from the MIP cavity,
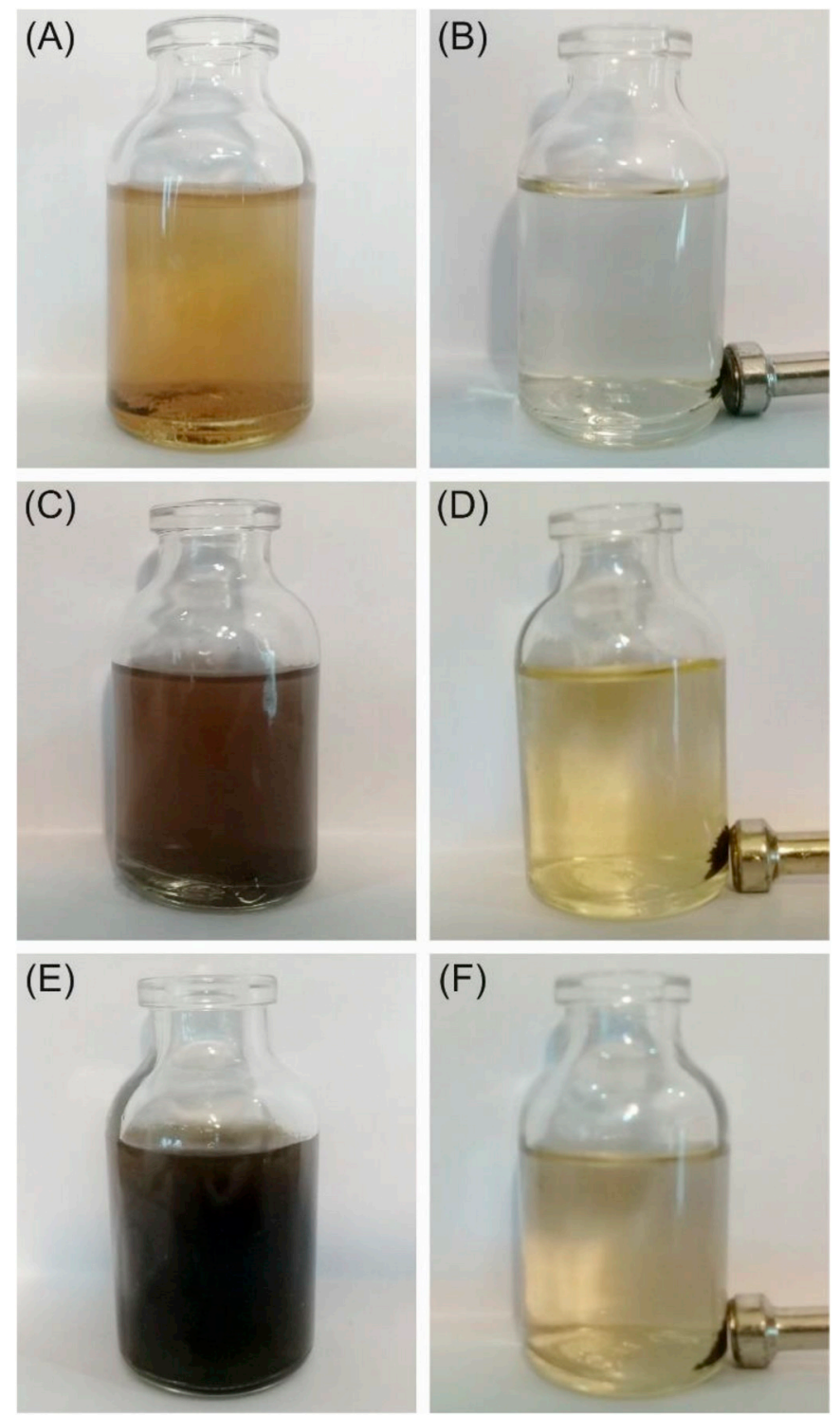

Fig. 3. The prepared $\mathrm{Fe}_{3} \mathrm{O}_{4}(\mathrm{~A}$ and $\mathrm{B}), \mathrm{APTS}-\mathrm{Fe}_{3} \mathrm{O}_{4}(\mathrm{C}$ and D) and $\mathrm{NCP}$ (E and $\mathrm{F}$ ), before ( $\mathrm{A}, \mathrm{C}$ and $\mathrm{E})$ and after (B, D and $\mathrm{F})$ magnet separation.

allows electrons to be easily transferred through the formed cavities at the surface of the sensor, leading in an improvement of the charge transfer rate. When the MIP-SPE was incubated with templates (PSA and Myo), the $\mathrm{R}_{\mathrm{ct}}$ value remarkably increased, which proved that specific interaction between analytes and MIP cavities take place.

Subsequently, the interaction of MIP(PSA, Myo)-SPE with NCP (curve $\mathrm{F}$ ) decreased the $\mathrm{R}_{\mathrm{ct}}$ values because of the high conductivity of GO and MWCNT that they can facilitate the electron transfer through the sensing layer. Interestingly, two semicircles appeared for NCP-MIP (PSA, Myo)-SPE, which is probably the result of the poor binding at the interface between NCP and MIP(PSA, Myo)-SPE. However, only one semicircle appeared in the Nyquist plot of MIP(PSA, Myo)-SPE. The semicircle is closely associate with the electron-transfer process and the electrical conductivity of the sensor material. The two semicircles were observed because of the partial coating of GO surface by oxygen-containing functional groups and show that the two different steps of the reaction take place in the electron transfer process [43,44]. Fig. $1(\mathrm{H}$ and I) indicates the equivalent circuits used to fit the EIS spectra. In the equivalent circuit, $R_{s}$ is the resistance of the solution. The $R_{c t}$ and $C$ represent the resistance of the charge transfer and the double layer 
Table 1

The SPR fitting data results.

\begin{tabular}{|c|c|c|c|c|c|}
\hline Binding site & Ligand & $\mathrm{K}_{\mathrm{a}}\left(\mathrm{M}^{-1} \mathrm{~s}^{-1}\right)$ & $\mathrm{K}_{\mathrm{d}}\left(\mathrm{s}^{-1}\right)$ & $\mathrm{K}_{\mathrm{D}}(\mathrm{M})$ & $\mathrm{K}_{\mathrm{A}}\left(\mathrm{M}^{-1}\right)$ \\
\hline MIP-SPE & PSA & $1.01 \times 10^{4}$ & $3.59 \times 10^{-5}$ & $3.55 \times 10^{-9}$ & $2.82 \times 10^{8}$ \\
\hline MIP-SPE & Myo & $2.54 \times 10^{4}$ & $2.35 \times 10^{-5}$ & $9.25 \times 10^{-10}$ & $1.08 \times 10^{9}$ \\
\hline MIP(PSA)-SPE & NCP & $3.23 \times 10^{4}$ & $3.87 \times 10^{-6}$ & $1.20 \times 10^{-10}$ & $8.33 \times 10^{9}$ \\
\hline
\end{tabular}
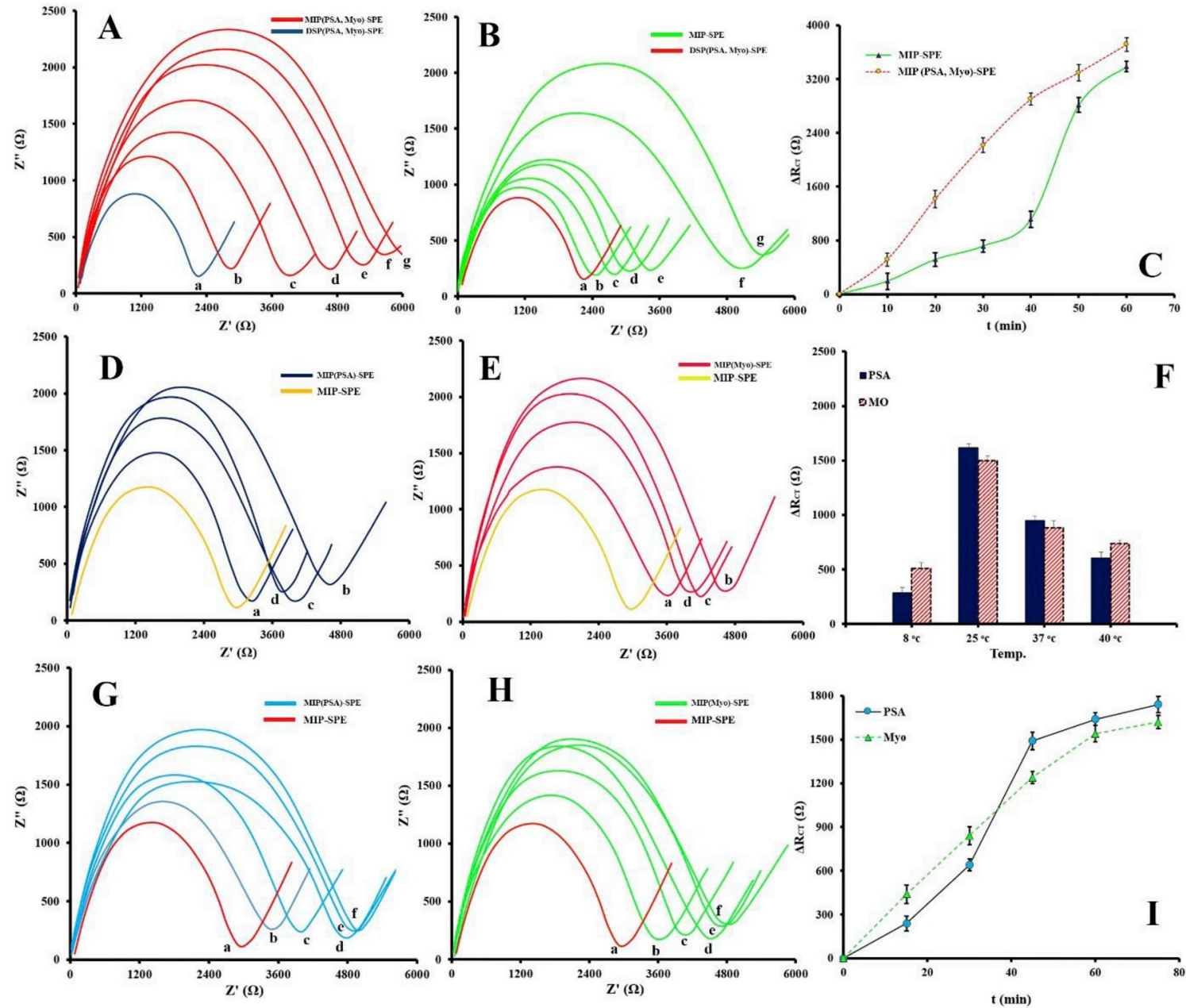

Fig. 4. EIS analysis results performed on DSP(PSA, Myo)-SPE during polymerization of MIP before (A) and after (B) incubation with OxA for different time points (0, $10,20,30,40,50$ and $60 \mathrm{~min}(\mathrm{a}-\mathrm{g})$ ). (C) The corresponding $\Delta \mathrm{R}_{\mathrm{ct}}$ results. EIS results from the study on temperature optimization for the interaction of (D) PSA and (E)

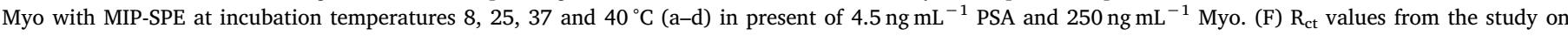
temperature optimization for the interaction of templates (PSA and MYO) with MIP-SPE. EIS results from the study on time optimization for the interaction of (G) PSA and (H) Myo with MIP-SPE at incubation time 0, 15, 30, 45, 60 and $75 \mathrm{~min}$ (a-e) in present of $4.5 \mathrm{ng} \mathrm{mL}{ }^{-1} \mathrm{PSA}$ and $250 \mathrm{ng} \mathrm{mL}^{-1} \mathrm{Myo}$. (I) $\mathrm{R}_{\mathrm{ct}}$ values from the study on time optimization for the interaction of templates (PSA and MYO) with MIP-SPE.

capacitance at the electrodes respectively, and $\mathrm{W}$ is the Warburg impedance. The calculated values of $\mathrm{R}_{s}, \mathrm{R}_{\mathrm{ct}} \mathrm{C}$ and $\mathrm{W}$ were listed in Table S1.

\subsubsection{SEM analysis}

To characterize surface features of NCP, SPE, MIP-SPE, and NCPMIP-SPE, SEM analysis was performed. SEM image of the synthesized NCP is represented in Fig. 1, Panel A. The results indicates the presence of MWCNT, GO, and $\mathrm{Fe}_{3} \mathrm{O}_{4}$ nanoparticles. $\mathrm{Fe}_{3} \mathrm{O}_{4}$ can be distributed on the MWCNT and GO surface and/or placed inside MWCNT and GO structure. Panel B shows a SEM image of bare SPE with smooth surfaces. Panel E illustrates a SEM image of MIP-SPE with a dense, scaly, and porous surface appeared, which was distributed homogeneously on the surface of SPE. As can be seen in Panel G, NCPs are successfully attached to the MIP-SPE. This binding can be the result of an immune reaction between antibody conjugated NCP and PSA.

\subsubsection{DLS analysis}

As can be seen in Fig. 2, evaluation of size distribution demonstrated the mean diameters of $\mathrm{Fe}_{3} \mathrm{O}_{4}$ (Panel A) and $\mathrm{Fe}_{3} \mathrm{O}_{4}$ modified with 3(Trimethoxysilyl)-propylamine (APTS) (Panel B) were 27 and $30 \mathrm{~nm}$, respectively. These results display that the $\mathrm{Fe}_{3} \mathrm{O}_{4}$ and $\mathrm{APTS}-\mathrm{Fe}_{3} \mathrm{O}_{4}$ have a similar size distribution. Modification of the $\mathrm{APTS}-\mathrm{Fe}_{3} \mathrm{O}_{4}$ using MWCNT, GO and $\mathrm{Ab}$ (Panel $\mathrm{C}$ ), leads to the slightly increase in the mean diameters and appearance of two size distribution with the mean center of $75 \mathrm{~nm}$ and $6.8 \mu \mathrm{m}$ related to length and diameters of NCP. 

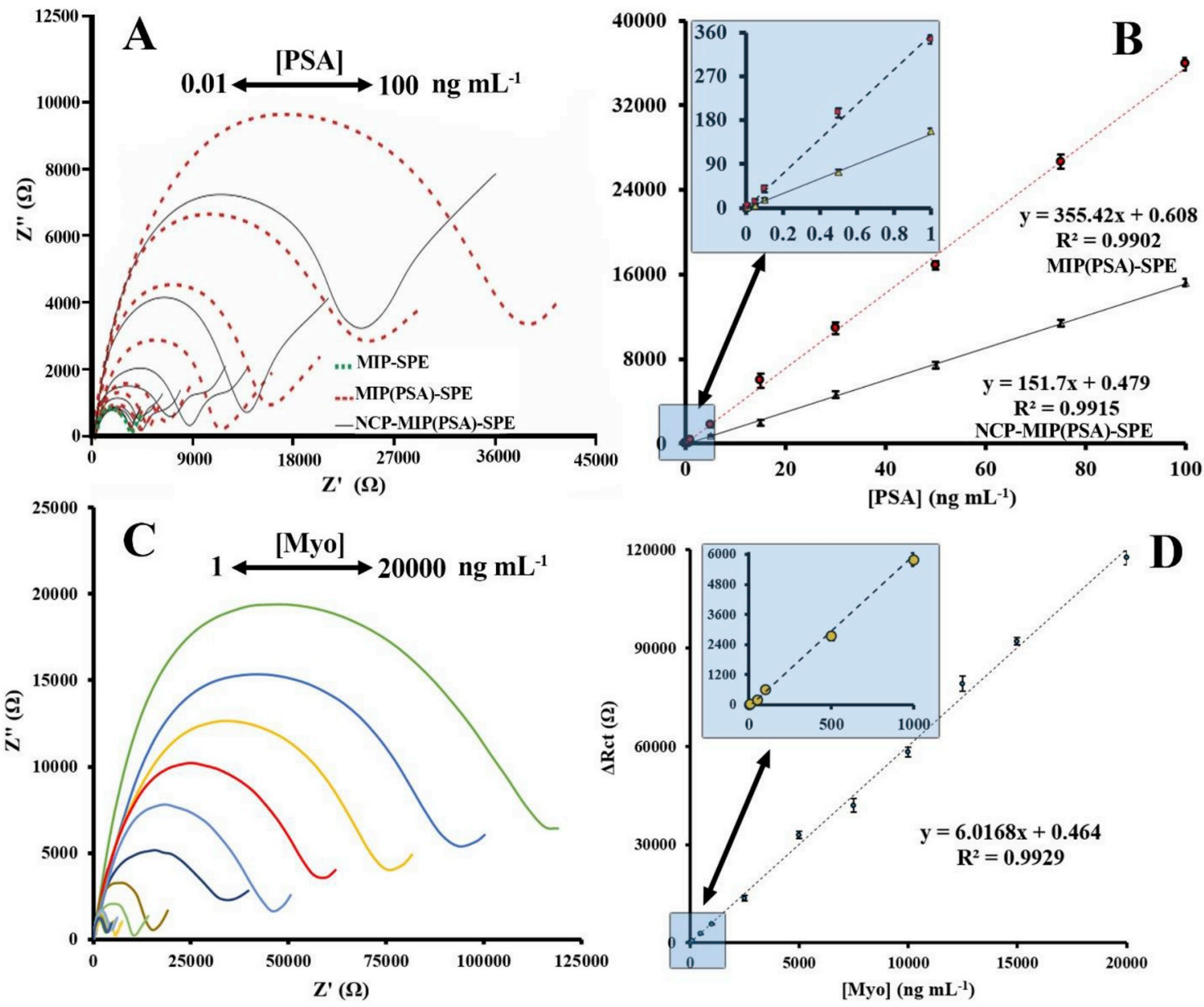

Fig. 5. (A) EIS results for different concentrations of PSA (0.01-100 $\mathrm{ng} \mathrm{mL}^{-1}$ ) using MIP(PSA)-SPE and NCP-MIP(PSA)-SPE (B) Calibration curve of the PSA analysis using MIP(PSA)-SPE and NCP-MIP(PSA)-SPE (C) EIS results for different concentrations of Myo (1-20000 ng mL ${ }^{-1}$ ) using MIP(Myo)-SPE (D) Calibration curve of the Myo analysis.

To further investigate the quality of synthesized Nanomaterials, they were dispersed in the water, and the effect of external magnetic field on the solutions was investigated. Fig. 3 (Panel A), represents the solution obtained after the dispersion of $\mathrm{Fe}_{3} \mathrm{O}_{4}$ nanoparticles in water. Panel B indicates that the separation of nanoparticles can be achieved by an external magnetic field. When APTS modified the $\mathrm{Fe}_{3} \mathrm{O}_{4}$, Panel C, showed better dispersibility and can be recovered using the external magnetic field (Panel D). Furthermore, NCP was dispersed in water, resulting in a black dispersion Fig. 3 (Panel E). Then a magnet was placed near the vessel to collect the nanoparticles within about $3 \mathrm{~min}$, the nanoparticles were completely collect to the cuvette wall, and the dispersion turns to the clear and transparent solution. The results showed that $\mathrm{Fe}_{3} \mathrm{O}_{4}$ nanoparticles decorated with MWCNT-GO and the obtained composite mantained the stability and magnetic properties a long time.

\subsubsection{SPR analysis}

To evaluate the binding affinity of MIP toward an analytical sample (PSA and Myo) and affinity between PSA and NCP, the kinetic function of an SPR spectrometer used to calculate the binding parameters. The resulting data (Table 1 ) was fitted to a simple bimolecular model, and the $\mathrm{k}_{\mathrm{a}}$ (association) and $\mathrm{k}_{\mathrm{d}}$ (dissociation) were obtained. The dissociation constant $\left(\mathrm{K}_{\mathrm{D}}\right)$ and the association constant $\left(\mathrm{K}_{\mathrm{A}}\right)$ were determined based on the ratio $k_{d} / k_{a}$ and $k_{a} / k_{d}$ respectively. The results showed that affinity MIP to Myo is higher than PSA and affinity between PSA and NCP is higher than that of PSA and MIP.

\subsection{Optimization of the experimental parameters}

\subsubsection{Self-assembly of DSP on SPE}

Self-assembly of organic functional groups is a very versatile route for the construction of films with high stability and organization on the solid electrodes $[43,45]$. The sulfhydryl group in the DSP structure offers a helpful tool for the binding of proteins to the surface of the gold electrodes. Furthermore, there is an ester group in the DSP structure which can bind to thiol or amine containing agents. To form the first layer on the electrode, the DSP was self-assembled on the SPE, and the peak density of DSP was tested using EIS to monitor the process completion. Fig. S1 represents the results of EIS analysis obtained during the self-assembly of DSP on the SPE at different incubation times.

The results showed that the $\mathrm{R}_{\mathrm{ct}}$ value increased with incubation time up to $60 \mathrm{~h}$, and then remained constant revealed that surface of SPE completely covered by self-assembled DSP. More investigations with the fitting of electrochemical impedance spectra proved that the electrode surface was anchored uniformly with DSP.

\subsubsection{The optimum time for assembling of PSA and Myo on DSP-SPE}

To fabricate the second layer of the sensing platform, PSA and Myo were allowed to covalently attach on the DSP-SPE, and EIS investigated the completion of the process. The influence of incubation time on the EIS signal was also studied. As can be seen from Fig. S2, as the incubation time increased up to $24 \mathrm{~h}$, the $\mathrm{R}_{\mathrm{ct}}$ increased. For longer incubation time, $R_{\mathrm{ct}}$ reached to the constant value. More investigation 
Table 2

Comparison of the proposed method with previously published electrochemical methods used for detection of PSA and Myo.

\begin{tabular}{|c|c|c|c|c|c|c|}
\hline WE & Analyte & Modifiers & $\mathrm{LOD}\left(\mathrm{pg} \mathrm{mL}^{-1}\right)$ & LOQ (ng mL ${ }^{-1}$ ) & Technic & Ref. \\
\hline $\mathrm{AuE}$ & \multirow[t]{16}{*}{ PSA } & Apt-MIP & 1 & $0.1-100$ & EIS & [46] \\
\hline GCE & & Au@Pt NCs-Ab & 18 & $0.1-50$ & DPV & [47] \\
\hline PGE & & PANI-AuNPs-PNT-Ab ${ }_{1}-\mathrm{Ab}_{2}$-HRP & 680 & $1-100$ & A & [29] \\
\hline $\mathrm{AuE}$ & & DNA-AgNPs-Apt & 0.11 & $0.001-160$ & LSV & [48] \\
\hline $\mathrm{AuE}$ & & GRP-PS $_{67}$-b-PAA 27 & 0.04 & $0.0001-100$ & EIS & [49] \\
\hline $\mathrm{AuE}$ & & MSTF-Apt & 280 & $1-300$ & DPV & {$[50]$} \\
\hline SPE & & AuNPs & 100 & $1-10$ & LSV & [51] \\
\hline SPE & & AuNPs-Apt-Au@ $@ \mathrm{Fe}_{3} \mathrm{O}_{4} \mathrm{NPs}-\mathrm{MB}$ & 0.0223 & $0.0001-10$ & SWV & {$[52]$} \\
\hline GCE & & Ag@MSN-GS@FCA & 2 & $0.01-10$ & A & [53] \\
\hline PtME & & SWCNTs-Ab & 250 & & DPV & [54] \\
\hline $\mathrm{AuE}$ & & $\mathrm{Ab}_{1}-\mathrm{Ab}_{2}-\mathrm{SiNPs}-\mathrm{ALP}$ & 760 & $1-35$ & LSV & [55] \\
\hline $\mathrm{AuE}$ & & Ab1-Ab2-ALP@LP & 7 & $0.01-100$ & LSV & [56] \\
\hline SPE & & $\mathrm{Fe}_{3} \mathrm{O}_{4}-\mathrm{Act}-\mathrm{Ab}_{1}-\mathrm{Ab}_{2}-\mathrm{Ab}_{3}-\mathrm{HRP}$ & $<100$ & $0-1$ & A & [57] \\
\hline SPE & & Ab1-Ab2-CdQDs & 200 & $0.5-80$ & SWV & {$[58]$} \\
\hline GCE & & Ag@MSN-Ab & 15 & $0.05-50$ & A & [59] \\
\hline SPE & & Ab-MWCNT-GO- $\mathrm{Fe}_{3} \mathrm{O}_{4}$-MIP & 5.4 & $0.01-100$ & EIS & This work \\
\hline GCE & \multirow[t]{6}{*}{ Myo } & Apt-AuNps-RGD-GR & $26.3 \mathrm{ng} \mathrm{mL}^{-1}$ & $100-200000$ & DPV & {$[60]$} \\
\hline SPE & & MIP(IL)-MWCNT & $9.7 \mathrm{nmol} \mathrm{L}^{-1}$ & $0.06-6 \mu \mathrm{mol} \mathrm{L}-1$ & DPV & [61] \\
\hline SPE & & TCPP-GR-AuNPs & $6.7 \mathrm{pmol} \mathrm{L}^{-1}$ & $0.02-770 \mathrm{nmol} \mathrm{L}^{-1}$ & DPV & [62] \\
\hline SPE & & MIP & $3.3 \mathrm{nmol} \mathrm{L}^{-1}$ & $1 \mathrm{nM}-1 \mu \mathrm{mol} \mathrm{L}-1$ & DPV & [63] \\
\hline SPE & & Apt & $27 \mathrm{pmol} \mathrm{L}^{-1}$ & $0.1-40 \mathrm{nmol} \mathrm{L}^{-1}$ & DPV & [64] \\
\hline SPE & & MIP & 830 & $1-20000$ & EIS & This work \\
\hline
\end{tabular}

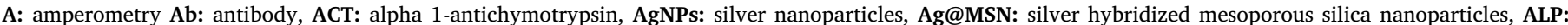

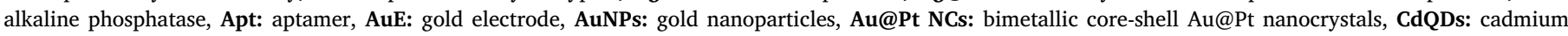

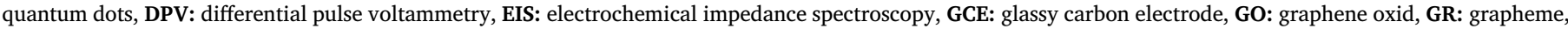

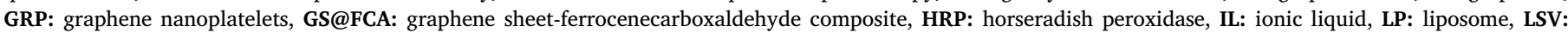

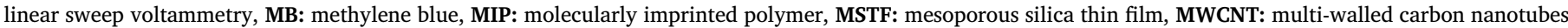

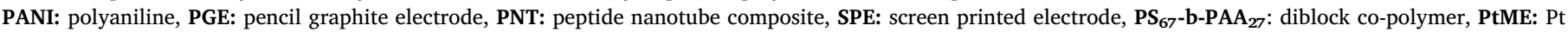

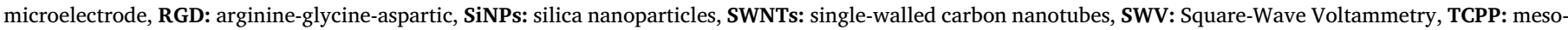
tetra (4-carboxyphenyl) porphyrin.

with the fitting of electrochemical impedance spectra showed that the DSP-SPE surface was covered uniformly with PSA and Myo.

\subsubsection{Engineering the thickness of polymerized MIP}

The influence of the imprinted polymer thickness on the response of the sensor was studied. Fig. 4 (Panel A-C) illustrates EIS analysis results obtained during polymerization of MIP on the DSP(PSA, Myo)-SPE before and after incubation with OxA. The polymerization was stopped at different time intervals by adding stop solution that leads to the formation of MIP with different width. As can be seen, the continuous growth of the thickness of MIP causes an increase in the $\mathrm{R}_{\mathrm{ct}}$ value, and the best result obtained when the polymerization process was allowed to proceed for $40 \mathrm{~min}$. Therefore, the optimum time of polymerization was chosen as $40 \mathrm{~min}$ it seems that the effective interaction between analytes and the solution take place in this thickness and more rise in polymerization time can mask the templates surface and notably increase $R_{\mathrm{ct}}$.

\subsubsection{Temperature and time optimization for the interaction of templates with MIP-SPE}

EIS methods were applied to investigate the complexation between templates (PSA and Myo) and MIP-SPE at five different temperatures. As shown in Fig. 4 (D-F) an increase in temperature cause rise in $R_{c t}$, reaching its highest value at $25^{\circ} \mathrm{C}$, revealing that maximum binding of templates to the MIP cavities take place at this temperature. However, at the higher temperature, a remarkable decline in $\mathrm{R}_{\mathrm{ct}}$ was observed, suggesting that, the elevated temperature may affect the interaction of MIP and templates. Therefore, the optimized temperature was chosen as $25^{\circ} \mathrm{C}$.

Furthermore, the effect of incubation time of MIP-SPE with analytes on the EIS responses was evaluated. It is found that (Fig. 4 (G-I)), the optimal incubation time is $60 \mathrm{~min}$ and it was chosen for the subsequent experiment.

\subsubsection{Temperature and time optimization for the interaction of NCP with MIP(PSA)-SPE}

To examine the effect of incubation temperature on the EIS response of the MIP(PSA)-SPE, the imprinted sensor was incubated with NCP at five different temperatures. As shown in Fig. S3, the $\Delta R_{c t}$ value increased with the increasing temperatures and reached a maximum at $37^{\circ} \mathrm{C}$. However, when raising the temperature from $37^{\circ} \mathrm{C}$ to $45^{\circ} \mathrm{C}$, the $\Delta \mathrm{R}_{\mathrm{ct}}$ significantly declined. This is presumably due to decreasing Antibody stability with increasing temperature. So the incubation temperature of $37^{\circ} \mathrm{C}$ was chosen as the optimal temperatures in the experiment.

The influence of incubation time with NCP from 0 to $150 \mathrm{~min}$ was studied (Fig. S4). The results showed that the MIP(PSA)-SPE response surged as the incubation time increased from 0 to 90 and no significant change was observed from 90 to $150 \mathrm{~min}$, proving that nearly all binding sites on MIP(PSA)-SPE were covered. Therefore, an incubation time of $90 \mathrm{~min}$ was used in the following experiment.

\subsection{Analytical application}

\subsubsection{Calibration curve and $L O D$}

Fig. 5 (A, B) illustrates the EIS and $\Delta \mathrm{R}_{\mathrm{ct}}$ results of different concentrations of PSA using MIP(PSA)-SPE and NCP-MIP(PSA)-SPE. The obtained signals were found to be linear in the ranges of $0.01-100 \mathrm{ng} \mathrm{mL}^{-1}$ with LOD of $5.4 \mathrm{pg} \mathrm{mL}^{-1}$ for PSA with the linear regression equations of $\Delta \mathrm{R}_{\mathrm{ct}}(1)=355.42$ [PSA] $+0.608\left(\mathrm{R}^{2}=0.9902\right.$ $(\mathrm{n}=3))$ and $\Delta \mathrm{R}_{\mathrm{ct}}(2)=151.7[\mathrm{PSA}]+0.479\left(\mathrm{R}^{2}=0.9915(\mathrm{n}=3)\right)$ using MIP(PSA)-SPE and NCP-MIP(PSA)-SPE respectively.

Fig. 5 (C and D) represents the EIS and $\Delta R_{c t}$ results of different concentrations of Myo using MIP(Myo)-SPE. The linear range of the calibration curve is obtained from 1 to $20000 \mathrm{ng} \mathrm{mL}^{-1}$ with a LOD of $830 \mathrm{pg} \mathrm{mL}^{-1}$ for Myo with the linear regression equations of $\Delta \mathrm{R}_{\mathrm{ct}}(3)=6.0168[\mathrm{Myo}]+0.464\left(\mathrm{R}^{2}=0.9929(\mathrm{n}=3)\right)$ using MIP (Myo)-SPE. 

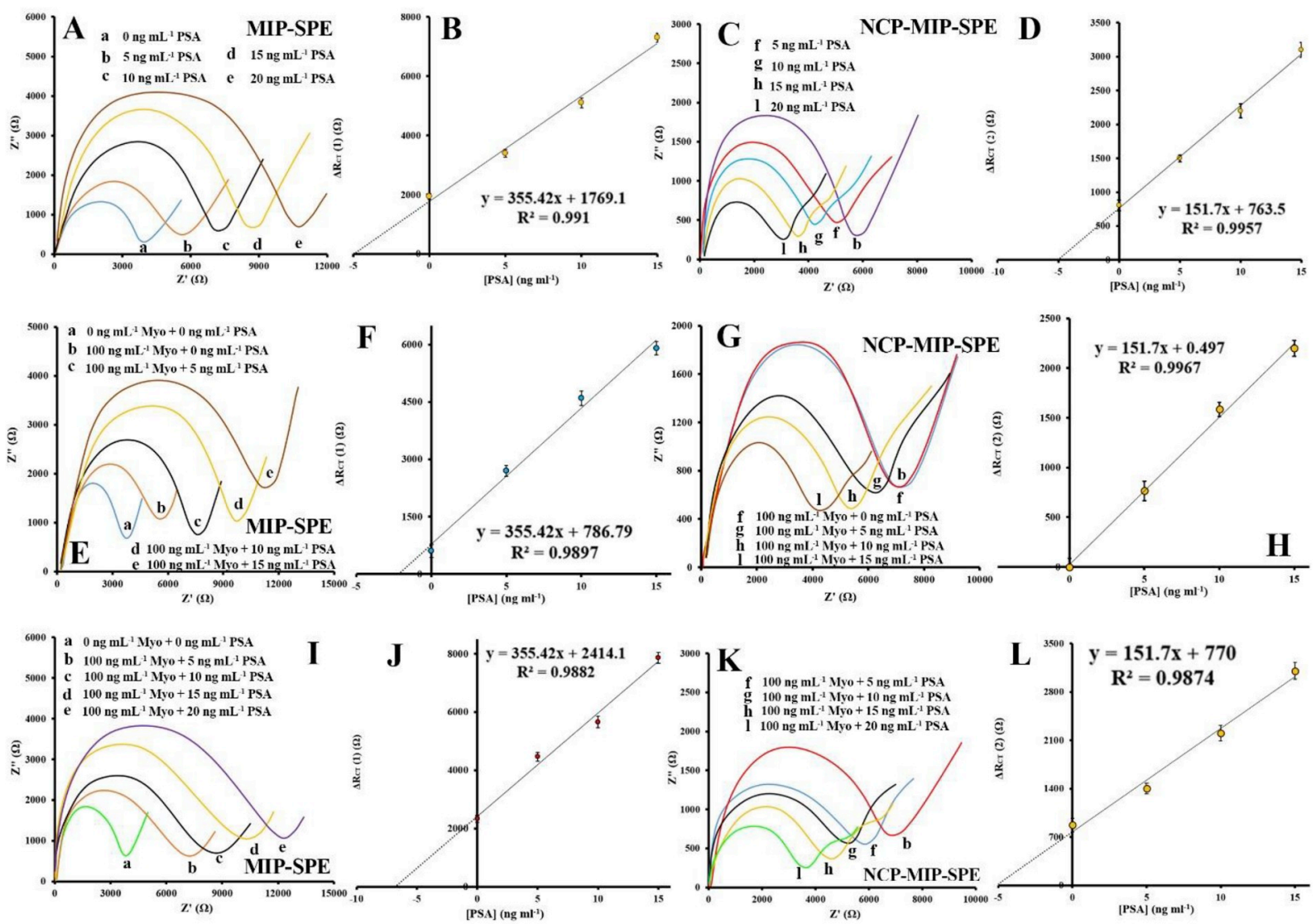

Fig. 6. Standard addition of PSA to the solution containing PSA. EIS results for standard addition of different concentrations of PSA (0 (a), 5 (b, f), 10 (c, g), 15 (d, h) and $20 \mathrm{ng} \mathrm{mL}^{-1}$ (e, I) using (A) MIP-SPE (C) NCP-MIP-SPE. Correspond calibration curve of (B) MIP-SPE (D) NCP-MIP-SPE. Standard addition of PSA for a solution containing Myo. EIS results for standard addition of different concentrations of PSA (0 (a, b, F), 5 (c, g), 10 (d, h) and $15 \mathrm{ng} \mathrm{mL}^{-1}$ (e, I) in the absent (a) and present (b-I) of $100 \mathrm{ng} \mathrm{mL} \mathrm{mL}^{-1}$ Myo using (E) MIP-SPE (G) NCP-MIP-SPE. Correspond calibration curve of (F) MIP-SPE (H) NCP-MIP-SPE. Standard addition of PSA for a solution containing PSA and Myo. EIS results for standard addition of different concentrations of PSA (0 (a), 5 (b, f), 10 (c, g), 15 (d, h) and 20 ng mL ( $^{-1}$ (e, I) in the absent (a) and present (b-I) of $100 \mathrm{ng} \mathrm{mL}^{-1}$ Myo using (I) MIP-SPE (K) NCP-MIP-SPE. Correspond calibration curve of (J) MIP-SPE (L) NCP-MIP-SPE.

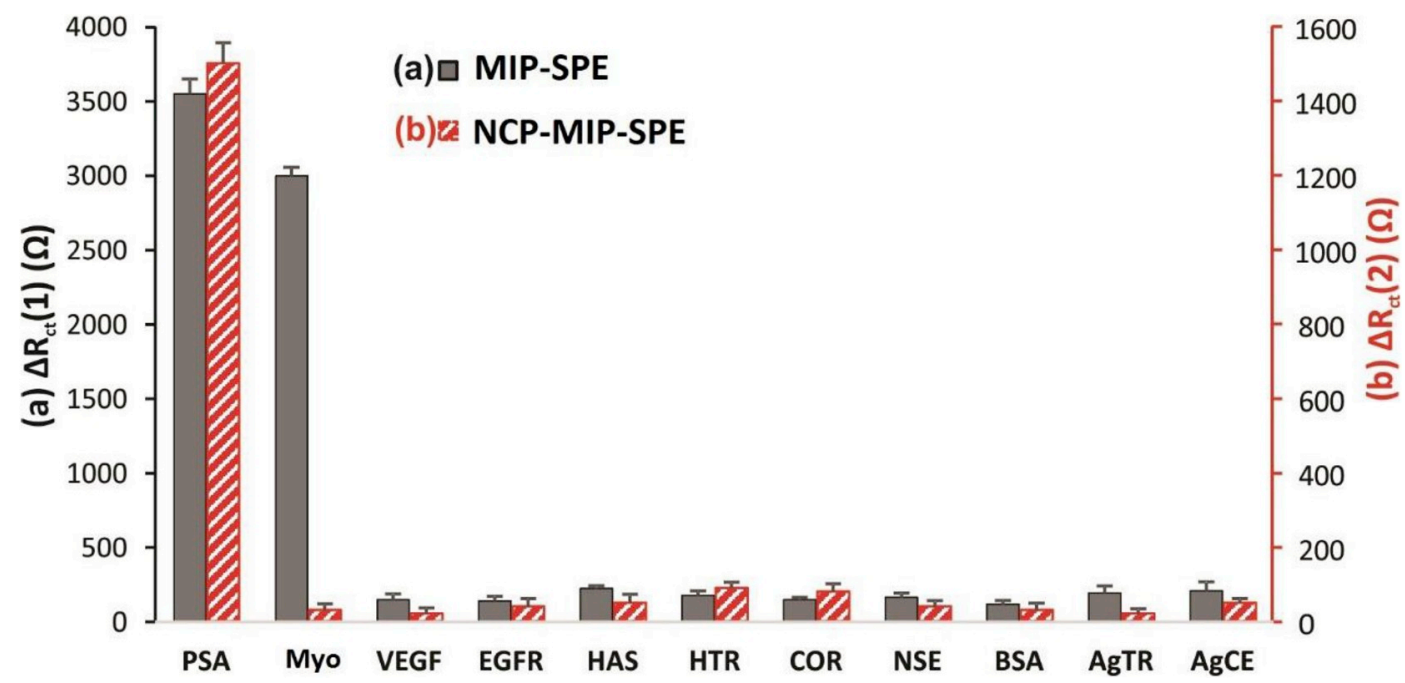

Fig. 7. Interference study for the sensor and immunosensor. The $\Delta \mathrm{R}_{\mathrm{ct}}$ of the MIP-SPE (a) and the NCP-MIP-SPE (b) for $10 \mathrm{ng} \mathrm{mL}^{-1} \mathrm{PSA}$ and $450 \mathrm{ng} \mathrm{mL}^{-1} \mathrm{Myo}$ in the presence of $6000 \mathrm{ng} \mathrm{mL}^{-1}$, EGFR, VEGF, COR, NSE, PSA, HTR, HAS, BSA, AgTR and AgCE.

In comparison to reported PSA and Myo sensors/biosensors, are shown in Table 2, developed immunosensor exhibits some superiorities regarding sensitivity, selectivity, reproducibility, and LOD over other PSA and Myo biosensors.

Also, determination of PSA and Myo concentration in the presence of each other were investigated. To this end, first, we determined the original content of PSA in the sample by the standard addition method using MIP(PSA, Myo)-SPE and NCP-MIP(PSA, Myo)-SPE. The concentration of PSA ([PSA]) was determined using a value of $\Delta \mathrm{R}_{\mathrm{ct}}(2)$ by NCP-MIP(PSA)-SPE with the linear regression equations of $\Delta \mathrm{R}_{\mathrm{ct}}(2)=151.7[\mathrm{PSA}]+0.479$. Then $\Delta \mathrm{R}_{\mathrm{ct}}(3)$ for Myo was calculated using MIP(PSA, Myo)-SPE and $\Delta \mathrm{R}_{\mathrm{ct}}(1)$ by linear regression equations of 
Table 3

Real samples analysis and comparison of the developed biosensor with a standard ELISA assay.

\begin{tabular}{|c|c|c|c|c|c|c|c|c|c|}
\hline Patient type & Sample type & $\begin{array}{l}\text { ELISA [PSA] (ng } \\
\mathrm{mL}^{-1} \text { ) }\end{array}$ & $\begin{array}{l}\text { ELISA [Myo] (ng } \\
\mathrm{mL}^{-1} \text { ) }\end{array}$ & $\begin{array}{l}\text { Added [PSA] } \\
\left(\mathrm{ng} \mathrm{mL} \mathrm{m}^{-1}\right)\end{array}$ & $\begin{array}{l}\text { Added [Myo] } \\
\left(\mathrm{ng} \mathrm{mL}^{-1}\right)\end{array}$ & $\begin{array}{l}\text { Found [PSA] (ng } \\
\mathrm{mL}^{-1} \text { ) }\end{array}$ & $\begin{array}{l}\text { Found [Myo] (ng } \\
\mathrm{mL}^{-1} \text { ) }\end{array}$ & PSA R(\%) & Myo R(\%) \\
\hline \multirow[t]{4}{*}{ CS } & Serum & $2.3 \pm 0.6$ & $65.6 \pm 1.2$ & 0 & 0 & $2.27 \pm 0.32$ & $67.52 \pm 1.45$ & 98.70 & 102.93 \\
\hline & Serum & $2.3 \pm 0.6$ & $65.6 \pm 1.2$ & 10 & 100 & $12.27 \pm 0.16$ & $165.7 \pm 0.98$ & 99.76 & 100.06 \\
\hline & Serum & $2.3 \pm 0.6$ & $65.6 \pm 1.2$ & 5 & 50 & $7.39 \pm 0.25$ & $116.92 \pm 1.01$ & 101.23 & 101.14 \\
\hline & Urine & ND & ND & 0 & 0 & 0 & 0 & ND & ND \\
\hline \multirow[t]{2}{*}{ PC } & Serum & $10.4 \pm 0.2$ & $86.4+2.3$ & 0 & 0 & $10.21 \pm 0.23$ & $87.10 \pm 1.54$ & 98.17 & 100.81 \\
\hline & Urine & $52.8 \pm 0.5$ & ND & 0 & 0 & $52.13 \pm 0.64$ & 0 & 98.73 & ND \\
\hline \multirow[t]{4}{*}{ BPH } & Serum & $5.1 \pm 0.3$ & $34.7 \pm 0.9$ & 0 & 0 & $5.23 \pm 0.78$ & $35.26 \pm 0.67$ & 102.55 & 101.61 \\
\hline & Serum & $5.1 \pm 0.3$ & $34.7 \pm 0.9$ & 5 & 50 & $10.24 \pm 0.92$ & $83.89 \pm 1.14$ & 101.39 & 99.04 \\
\hline & Serum & $5.1 \pm 0.3$ & $34.7 \pm 0.9$ & 10 & 100 & $15.41 \pm 0.94$ & $133.21 \pm 1.20$ & 102.05 & 98.89 \\
\hline & urine & $94.6 \pm 0.8$ & ND & 0 & 0 & $95.21 \pm 0.35$ & 0 & 100.64 & ND \\
\hline \multirow[t]{2}{*}{ BLMS } & Serum & $3.8 \pm 0.1$ & $75.1 \pm 0.9$ & 0 & 0 & $3.91 \pm 0.41$ & $74.85 \pm 0.36$ & 102.89 & 99.68 \\
\hline & urine & $123.4 \pm 0.7$ & $435.9 \pm 0.6$ & 0 & 0 & $124.11+1.2$ & $437.15 \pm 2.25$ & 100.58 & 102.87 \\
\hline
\end{tabular}

BLMS: Bladder leiomyosarcoma, BPH: Benign prostatic hyperplasia, CS: Control subject, ND: Not determined, PC: Prostate cancer, R: Recovery.

$\Delta \mathrm{R}_{\mathrm{ct}}(3)=\Delta \mathrm{R}_{\mathrm{ct}}(1)-(355.42[\mathrm{PSA}]+0.608)$. Finally, the concentration of Myo ([Myo]) was determined using the value of $\Delta \mathrm{R}_{\mathrm{ct}}(3)$ and linear regression equations of $\Delta \mathrm{R}_{\mathrm{ct}}(3)=6.0168$ [Myo] +0.464 . The cross-effect of PSA and Myo on the calibration curves was investigated, and the results showed that there are no significant differences between slopes of the calibration curves (Fig. 6 and Table S2).

\subsubsection{Interference study}

To evaluate the selectivity of the MIP, different biomarkers such as bovine serum albumin (BSA), cortisol (COR), epidermal growth factor receptor (EGFR), carcinoembryonic antigen (AgCE), thrombin antigen (AgTA), human thrombin (HTR), vascular endothelial growth factor (VEGF), human albumin serum (HAS) and neuron-specific enolase (NSE) were used and comparison of performance of the proposed impedimetric immunosensor for determination of analytes and abovementioned biomarkers was performed. Fig. 7 depicts the results of EIS investigation of the developed MIP-SPE in the presence of potential interferences. The calculated $\Delta \mathrm{R}_{\mathrm{ct}}$ values of the MIP-SPE and NCP-MIPSPE in the solution of biomarkers were lower than those of PSA and Myo $(\mathrm{p}<0.06)$. The calculated $\Delta \mathrm{R}_{\mathrm{ct}}$ values of NCP-MIP-SPE in the solution of biomarkers were lower than those of PSA ( $p<0.04)$. The obtained results confirmed that the fabricated MIP has highly specific binding capacity to target analytes and fabricated NCP has highly specific binding capacity to PSA.

\subsubsection{Real sample analysis}

To assess the analytical efficiency of developed immunosensor, determination of PSA and Myo concentration in serum and urine samples was performed. As can be seen in Table 3, the results obtained from developed impedimetric immunosensor and ELISA are in good agreement without significant difference $(\mathrm{p}<0.05)$. Furthermore, it should be noted that selectivity and sensitivity of the proposed method were not notably affected be other proteins present in the serum or urine samples.

\subsubsection{Accuracy, reproducibility, stability, and regeneration of the sensor and immunosensor}

In the repeated PSA or Myo analysis using the engineered sensor, the MIP-SPE and NCP-MIP-SPE can remain completely stable in the next PSA or Myo determination. Relative standard deviation (RSD) of this regeneration was found to be about 4.2 and $3.9(n=5)$ for PSA and Myo analysis respectively using MIP-SPE and $5.1(\mathrm{n}=5)$ for PSA using NCP-MIP-SPE. Moreover, reproducibility of sensor and immunosensor construction process were studied through the examination of MIP or NCP modified electrodes prepared independently. Inter-assay precision was found to be less than 4.9 and 5\% for MIP-SPE and NCP-MIP-SPE respectively. The stability of the sensor and immunosensor were investigated during 45 days by coefficient variation percentage (CV \%). In addition, the engineered MIP-SPE was highly stable during 30 days after preparation with $\mathrm{CV} \%$ less than $4.8 \%$. After 45 days, $\mathrm{CV} \%$ of measurements was less than $6 \%$. The engineered NCP was found to be extremely stable during 30 days post-fabrication with CV\% less than $5.2 \%$. After 45 days, CV\% of measurements was less than $6.8 \%$. All the obtained results on reproducibility, stability, and regeneration confirmed that the sensor and immunosensor engineering method as a sound sensing approach for detection of Myo and PSA in biological samples.

\section{Conclusion}

In this work, we described a novel impedimetric sensor and immunosensor for the dual detection of PSA and Myo using MIP-SPE and NCP-MIP-SPE. The polymer modified electrode (MIP-SPE) is highly sensitive for PSA and Myo. Engineered NCP provides high conductivity as the sensing interface, which could be sensitive for PSA. The sensor and immunosensor exhibited reasonable sensitivity, selectivity, and stability. An LDR $0.01-100 \mathrm{pg} \mathrm{mL}^{-1}$ and from 1 to $20000 \mathrm{pg} \mathrm{mL}-1$ were achieved for PSA and Myo respectively. The LOD was as low as $5.4 \mathrm{pg} \mathrm{mL}^{-1}$ and $0.83 \mathrm{ng} \mathrm{mL}^{-1}$ for PSA and Myo respectively. The immunosensor could be used for the detection of PSA and Myo in real samples.

\section{Acknowledgement}

The authors would like to thank National Institute for Medical Research Development (NIMAD) for the financial support this work (Grant No. 957699).

\section{Appendix A. Supplementary data}

Supplementary data related to this article can be found at https:// doi.org/10.1016/j.talanta.2019.04.061.

\section{References}

[1] M.J. Barry, Prostate-specific-antigen testing for early diagnosis of prostate cancer, N. Engl. J. Med. 344 (2002) 1373-1377, https://doi.org/10.1056/ nejm200105033441806.

[2] I.M. Thompson, D.K. Pauler, P.J. Goodman, C.M. Tangen, M.S. Lucia, H.L. Parnes, L.M. Minasian, L.G. Ford, S.M. Lippman, E.D. Crawford, J.J. Crowley, C.A. Coltman, Prevalence of prostate cancer among men with a prostate-specific antigen level $\leq 4.0$ ng per milliliter, N. Engl. J. Med. 350 (2004) 2239-2246, https://doi.org/10. 1056/NEJMoa031918.

[3] M.J. Stone, M.R. Waterman, D. Harimoto, G. Murray, N. Willson, M.R. Platt, G. Blomqvist, J.T. Willerson, Serum myoglobin level as diagnostic test in patients with acute myocardial infarction, Br. Heart J. 39 (1977) 375, https://doi.org/10. 1136/hrt.39.4.375 LP - 380.

[4] T.G. Rosano, M.A. Kenny, A radioimmunoassay for human serum myoglobin: method development and normal values, Clin. Chem. 23 (1977) 69 LP - 75 http:// 
clinchem.aaccjnls.org/content/23/1/69.abstract.

[5] A.H. Wu, Y.J. Feng, J.H. Contois, S. Pervaiz, Comparison of myoglobin, creatine kinase-MB, and cardiac troponin I for diagnosis of acute myocardial infarction, Ann. Clin. Lab. Sci. 26 (1996) 291-300 http://www.annclinlabsci.org/content/26/4/ 291.abstract.

[6] S. Meller, A. Bicker, M. Montani, K. Ikenberg, B. Rostamzadeh, V. Sailer, P. Wild, D. Dietrich, B. Uhl, T. Sulser, H. Moch, T.A. Gorr, C. Stephan, K. Jung, T. Hankeln, G. Kristiansen, Myoglobin expression in prostate cancer is correlated to androgen receptor expression and markers of tumor hypoxia, Virchows Arch. 465 (2014) 419-427, https://doi.org/10.1007/s00428-014-1646-y.

[7] A. Bicker, A.M. Brahmer, S. Meller, G. Kristiansen, T.A. Gorr, T. Hankeln, The distinct gene regulatory network of myoglobin in prostate and breast cancer, PLoS One 10 (2015) e0142662, , https://doi.org/10.1371/journal.pone.0142662.

[8] A. Lindsay, S. Carr, N. Draper, S.P. Gieseg, Urinary myoglobin quantification by high-performance liquid chromatography: an alternative measurement for exerciseinduced muscle damage, Anal. Biochem. 491 (2015) 37-42, https://doi.org/10. 1016/j.ab.2015.09.001.

[9] H.C.B. Graves, M. Kamarei, T.A. Stamey, Identity of prostate specific antigen and the semen protein $\mathrm{p} 30$ purified by a rapid chromatography technique, J. Urol. 144 (1990) 1510-1515, https://doi.org/10.1016/S0022-5347(17)39788-4.

[10] B.M. Mayr, O. Kohlbacher, K. Reinert, M. Sturm, C. Gröpl, E. Lange, C. Klein, C.G. Huber, Absolute myoglobin quantitation in serum by combining two-dimensional liquid chromatography-electrospray ionization mass spectrometry and novel data analysis algorithms, J. Proteome Res. 5 (2006) 414-421, https://doi.org/10. 1021/pr050344u.

[11] J.J. Hlavaty, A.W. Partin, F. Kusinitz, M.J. Shue, A. Stieg, K. Bennett, J. V Briggman, Mass spectroscopy as a discovery tool for identifying serum markers for prostate cancer, Clin. Chem. 47 (2001) 1924 LP - 1926 http://clinchem.aaccjnls.org/ content/47/10/1924.abstract.

[12] A. Clerico, M.G. Del Chicca, G.C. Zucchelli, L. Salutini, A. Mercuri, M. Scarlattini, Performance of a fully automated fluorometric enzyme immunoassay for serum myoglobin measurement, J. Nucl. Biol. Med. 37 (1993) 83-87 http://europepmc. org/abstract/MED/8373838.

[13] Y. Wang, A. Brunsen, U. Jonas, J. Dostálek, W. Knoll, Prostate specific antigen biosensor based on long range surface plasmon-enhanced fluorescence spectroscopy and dextran hydrogel binding matrix, Anal. Chem. 81 (2009) 9625-9632, https:// doi.org/10.1021/ac901662e.

[14] E.E. Kline, E.G. Treat, T.A. Averna, M.S. Davis, A.Y. Smith, L.O. Sillerud, Citrate concentrations in human seminal fluid and expressed prostatic fluid determined via $1 \mathrm{H}$ nuclear magnetic resonance spectroscopy outperform prostate specific antigen in prostate cancer detection, J. Urol. 176 (2006) 2274-2279, https://doi.org/10. 1016/j.juro.2006.07.054

[15] J.H. Bradbury, S.L.M. Deacon, M.D. Ridgway, Histidine residues of myoglobin studied by $1 \mathrm{H}$ nuclear magnetic resonance spectroscopy, J. Chem. Soc., Chem. Commun. (1979) 997-998, https://doi.org/10.1039/C39790000997.

[16] G. Koukouvinos, A. Metheniti, C.E. Karachaliou, D. Goustouridis, E. Livaniou, K. Misiakos, I. Raptis, A. Kondili, P. Miniati, P. Petrou, S. Kakabakos, White ligh reflectance spectroscopy biosensing system for fast quantitative prostate specific antigen determination in forensic samples, Talanta 175 (2017) 443-450, https:// doi.org/10.1016/j.talanta.2017.07.074.

[17] M.J. Donohue, M.B. Satterfield, J.J. Dalluge, M.J. Welch, J.E. Girard, D.M. Bunk Capillary electrophoresis for the investigation of prostate-specific antigen heterogeneity, Anal. Biochem. 339 (2005) 318-327, https://doi.org/10.1016/j.ab.2005 01.043.

[18] W. Jin, Q. Dong, D. Yu, X. Ye, Monitoring myoglobin by capillary zone electrophoresis with end-column amperometric detection, Electrophor. An Int. J. 21 (2000) 1535-1539.

[19] L. Niu, Z. Song, X. He, A study of the chemiluminescence behavior of cephalosporins with luminol and its analytical application, Drug Metab. Lett. 3 (2009) 144-151, https://doi.org/10.2174/187231209789352157.

[20] L.I. Stowell, L.E. Sharman, K. Hamel, An enzyme-linked immunosorbent assay (ELISA) for prostate-specific antigen, Forensic Sci. Int. 50 (1991) 125-138, https:// doi.org/10.1016/0379-0738(91)90141-5.

[21] T. Kitao, S. Miyaishi, H. Ishizu, Identification of human skeletal muscle from a tissue fragment by detection of human myoglobin using a double-sandwich ELISA, Forensic Sci. Int. 71 (1995) 205-214, https://doi.org/10.1016/0379-0738(94) 01667-4.

[22] M. Weber, M. Rau, K. Madlener, A. Elsaesser, D. Bankovic, V. Mitrovic, C. Hamm, Diagnostic utility of new immunoassays for the cardiac markers cTnI, myoglobin and CK-MB mass, Clin. Biochem. 38 (2005) 1027-1030, https://doi.org/10.1016/j clinbiochem.2005.07.011.

[23] F. Zhang, L. Mao, M. Zhu, Ultrasensitive immunoassay for free prostate-specific antigen based on ferrocenecarboxylate enhanced cathodic electrochemiluminescence of peroxydisulfate, Microchim. Acta. 181 (2014) 1285-1291, https://doi.org/10.1007/s00604-014-1240-7.

[24] L.E. Roxin, P. Venge, L. Wide, A fast and sensitive radioimmunoassay of human myoglobin for use in the early diagnosis of heart infarction, Clin. Chim. Acta 107 (1980) 129-134, https://doi.org/10.1016/0009-8981(80)90422-2.

[25] G. Sun, H. Liu, Y. Zhang, J. Yu, M. Yan, X. Song, W. He, Gold nanorods-paper electrode based enzyme-free electrochemical immunoassay for prostate specific antigen using porous zinc oxide spheres-silver nanoparticles nanocomposites as labels, New J. Chem. 39 (2015) 6062-6067, https://doi.org/10.1039/c5nj00629e.

[26] T. Soukka, J. Paukkunen, H. Härmä, S. Lönnberg, H. Lindroos, T. Lövgren, Supersensitive time-resolved immunofluorometric assay of free prostate-specific antigen with nanoparticle label technology, Clin. Chem. 47 (2001) 1269-1278.

[27] T. Kaya, T. Kaneko, S. Kojima, Y. Nakamura, Y. Ide, K. Ishida, Y. Suda,
K. Yamashita, High-sensitivity immunoassay with surface plasmon field-enhanced fluorescence spectroscopy using a plastic sensor chip: application to quantitative analysis of total prostate-specific antigen and GalNAc $31-4 \mathrm{GlcNAc}-$ linked prostatespecific antigen for prost, Anal. Chem. 87 (2015) 1797-1803, https://doi.org/10. 1021/ac503735e.

[28] Y. Seto, T. Iba, K. Abe, Development of ultra-high sensitivity bioluminescent enzyme immunoassay for prostate-specific antigen (PSA) using firefly luciferase, Luminescence 16 (2001) 285-290, https://doi.org/10.1002/bio.654.

[29] T. Vural, Y.T. Yaman, S. Ozturk, S. Abaci, E.B. Denkbas, Electrochemical immunoassay for detection of prostate specific antigen based on peptide nanotubegold nanoparticle-polyaniline immobilized pencil graphite electrode, J. Colloid Interface Sci. 510 (2018) 318-326, https://doi.org/10.1016/j.jcis.2017.09.079.

[30] Z. Chaloupková, A. Balzerová, J. Bařinková, Z. Medř́ková, P. Šácha, P. Beneš, V. Ranc, J. Konvalinka, R. Zbořil, Label-free determination of prostate specific membrane antigen in human whole blood at nanomolar levels by magnetically assisted surface enhanced Raman spectroscopy, Anal. Chim. Acta 997 (2018) 44-51, https://doi.org/10.1016/j.aca.2017.10.008.

[31] J.H. Lee, K.S. Hwang, J. Park, K.H. Yoon, D.S. Yoon, T.S. Kim, Immunoassay of prostate-specific antigen (PSA) using resonant frequency shift of piezoelectric nanomechanical microcantilever, Biosens. Bioelectron. 20 (2005) 2157-2162, https:// doi.org/10.1016/j.bios.2004.09.024.

[32] M.R. Majidi, P. Karami, M. Johari-Ahar, Y. Omidi, Direct detection of tryptophan for rapid diagnosis of cancer cell metastasis competence by an ultra-sensitive and highly selective electrochemical biosensor, Anal. Methods. 8 (2016) 7910-7919, https://doi.org/10.1039/c6ay02103d.

[33] H. Bagheri, A. Afkhami, H. Khoshsafar, A. Hajian, A. Shahriyari, A. Hajian, Protein capped $\mathrm{Cu}$ nanoclusters-SWCNT nanocomposite as a novel candidate of high performance platform for organophosphates enzymeless biosensor, Biosens. Bioelectron. 89 (2016) 829-836, https://doi.org/10.1016/j.bios.2016.10.003.

[34] A. Afkhami, P. Hashemi, H. Bagheri, J. Salimian, A. Ahmadi, T. Madrakian, Impedimetric immunosensor for the label-free and direct detection of botulinum neurotoxin serotype A using Au nanoparticles/graphene-chitosan composite, Biosens. Bioelectron. 93 (2017) 124-131, https://doi.org/10.1016/j.bios.2016.09. 059.

[35] M. Johari-Ahar, M.R. Rashidi, J. Barar, M. Aghaie, D. Mohammadnejad, A. Ramazani, P. Karami, G. Coukos, Y. Omidi, An ultra-sensitive impedimetric immunosensor for detection of the serum oncomarker CA-125 in ovarian cancer patients, Nanoscale 7 (2015), https://doi.org/10.1039/c4nr06687a.

[36] P. Karami, M.R. Majidi, M. Johari-Ahar, J. Barar, Y. Omidi, Development of screen printed tryptophan-kynurenine immunosensor for in vitro assay of kynureninemediated immunosuppression effect of cancer cells on activated T-cells, Biosens, Bioelectron 92 (2017) 287-293, https://doi.org/10.1016/j.bios.2016.11.010.

[37] M.R. Majidi, Y. Omidi, P. Karami, M. Johari-Ahar, Reusable potentiometric screenprinted sensor and label-free aptasensor with pseudo-reference electrode for determination of tryptophan in the presence of tyrosine, Talanta 150 (2016) 425-433, https://doi.org/10.1016/j.talanta.2015.12.064.

[38] J.G. Pacheco, M.S.V. Silva, M. Freitas, H.P.A. Nouws, C. Delerue-Matos, Molecularly imprinted electrochemical sensor for the point-of-care detection of a breast cancer biomarker (CA 15-3), Sensor. Actuator. B Chem. 256 (2018) 905-912, https://doi. org/10.1016/j.snb.2017.10.027.

[39] M. Johari-Ahar, P. Karami, M. Ghanei, A. Afkhami, H. Bagheri, Development of a molecularly imprinted polymer tailored on disposable screen-printed electrodes for dual detection of EGFR and VEGF using nano-liposomal amplification strategy, Biosens. Bioelectron. 107 (2018) 26-33, https://doi.org/10.1016/j.bios.2018.02. 005.

[40] P. Palladino, M. Minunni, S. Scarano, Corrigendum to "Cardiac Troponin T capture and detection in real-time via epitope-imprinted polymer and optical biosensing", Biosens. Bioelectron. 106 (2018) 93-98, https://doi.org/10.1016/j.bios.2018.01. 068 S0956566318300812, Biosens. Bioelectron. 130 (2019) 427. doi:10.1016/j. bios.2019.02.011.

[41] R. Jalili, M. Amjadi, Bio-inspired molecularly imprinted polymer-green emitting carbon dot composite for selective and sensitive detection of 3-nitrotyrosine as a biomarker, Sensor. Actuator. B Chem. 255 (2018) 1072-1078, https://doi.org/10. 1016/j.snb.2017.08.145.

[42] F. Bonini, S. Piletsky, A.P.F. Turner, A. Speghini, A. Bossi, Surface imprinted beads for the recognition of human serum albumin, Biosens. Bioelectron. 22 (2007) 2322-2328, https://doi.org/10.1016/j.bios.2006.12.034.

[43] B. Yuan, C. Xu, D. Deng, Y. Xing, L. Liu, H. Pang, D. Zhang, Graphene oxide/nickel oxide modified glassy carbon electrode for supercapacitor and nonenzymatic glucose sensor, Electrochim. Acta 88 (2013) 708-712, https://doi.org/10.1016/j. electacta.2012.10.102.

[44] E. Casero, A.M. Parra-Alfambra, M.D. Petit-Domínguez, F. Pariente, E. Lorenzo, C. Alonso, Differentiation between graphene oxide and reduced graphene by electrochemical impedance spectroscopy (EIS), Electrochem. Commun. 20 (2012) 63-66, https://doi.org/10.1016/j.elecom.2012.04.002.

[45] M. Frasconi, F. Mazzei, T. Ferri, Protein immobilization at gold-thiol surfaces and potential for biosensing, Anal. Bioanal. Chem. 398 (2010) 1545-1564, https://doi. org/10.1007/s00216-010-3708-6.

[46] P. Jolly, V. Tamboli, R.L. Harniman, P. Estrela, C.J. Allender, J.L. Bowen, AptamerMIP hybrid receptor for highly sensitive electrochemical detection of prostate specific antigen, Biosens. Bioelectron. 75 (2016) 188-195, https://doi.org/10. 1016/j.bios.2015.08.043.

[47] R. Wang, A.J. Wang, W.D. Liu, P.X. Yuan, Y. Xue, X. Luo, J.J. Feng, A novel labelfree electrochemical immunosensor for ultra-sensitively detecting prostate specific antigen based on the enhanced catalytic currents of oxygen reduction catalyzed by core-shell Au@Pt nanocrystals, Biosens. Bioelectron. 102 (2018) 276-281, https:// 
doi.org/10.1016/j.bios.2017.11.041.

[48] P. Miao, Y. Jiang, Y. Wang, J. Yin, Y. Tang, An electrochemical approach capable of prostate specific antigen assay in human serum based on exonuclease-aided target recycling amplification, Sensor. Actuator. B Chem. 257 (2018) 1021-1026, https:// doi.org/10.1016/j.snb.2017.11.064.

[49] M.S. Khan, K. Dighe, Z. Wang, I. Srivastava, E. Daza, A.S. Schwartz-Dual, J. Ghannam, S.K. Misra, D. Pan, Detection of prostate specific antigen (PSA) in human saliva using an ultra-sensitive nanocomposite of graphene nanoplatelets with diblock-: Co -polymers and Au electrodes, Analyst 143 (2018) 1094-1103, https://doi.org/10.1039/c7an01932g.

[50] W. Argoubi, A. Sánchez, C. Parrado, N. Raouafi, R. Villalonga, Label-free electrochemical aptasensing platform based on mesoporous silica thin film for the detection of prostate specific antigen, Sensor. Actuator. B Chem. 255 (2018) 309-315, https://doi.org/10.1016/j.snb.2017.08.045.

[51] V. Escamilla-Gómez, D. Hernández-Santos, M.B. González-García, J.M. PingarrónCarrazón, A. Costa-García, Simultaneous detection of free and total prostate specific antigen on a screen-printed electrochemical dual sensor, Biosens. Bioelectron. 24 (2009) 2678-2683, https://doi.org/10.1016/j.bios.2009.01.043.

[52] C.Y. Lee, H.T. Fan, Y.Z. Hsieh, Disposable aptasensor combining functional magnetic nanoparticles with rolling circle amplification for the detection of prostatespecific antigen, Sensor. Actuator. B Chem. 255 (2018) 341-347, https://doi.org/ 10.1016/j.snb.2017.08.061.

[53] Y. Li, J. Han, R. Chen, X. Ren, Q. Wei, Label electrochemical immunosensor for prostate-specific antigen based on graphene and silver hybridized mesoporous silica, Anal. Biochem. 469 (2015) 76-82, https://doi.org/10.1016/j.ab.2014.09.022.

[54] J. Okuno, K. Maehashi, K. Kerman, Y. Takamura, K. Matsumoto, E. Tamiya, Labelfree immunosensor for prostate-specific antigen based on single-walled carbon nanotube array-modified microelectrodes, Biosens. Bioelectron. 22 (2007) 2377-2381, https://doi.org/10.1016/j.bios.2006.09.038.

[55] B. Qu, X. Chu, G. Shen, R. Yu, A novel electrochemical immunosensor based on colabeled silica nanoparticles for determination of total prostate specific antigen in human serum, Talanta 76 (2008) 785-790, https://doi.org/10.1016/j.talanta.2008. 04.026.

[56] B. Qu, L. Guo, X. Chu, D.H. Wu, G.L. Shen, R.Q. Yu, An electrochemical immunosensor based on enzyme-encapsulated liposomes and biocatalytic metal deposition, Anal. Chim. Acta 663 (2010) 147-152, https://doi.org/10.1016/j.aca. 2010.01.050.

[57] P. Sarkar, D. Ghosh, D. Bhattacharyay, S.J. Setford, A.P.F. Turner, Electrochemical immunoassay for free prostate specific antigen (f-PSA) using magnetic beads, Electroanalysis 20 (2008) 1414-1420, https://doi.org/10.1002/elan.200804194.

[58] J. Wang, G. Liu, H. Wu, Y. Lin, Quantum-dot-based electrochemical immunoassay for high-throughput screening of the prostate-specific antigen, Small 4 (2008) 82-86, https://doi.org/10.1002/smll.200700459.

[59] H. Wang, Y. Zhang, H. Yu, D. Wu, H. Ma, H. Li, B. Du, Q. Wei, Label-free electrochemical immunosensor for prostate-specific antigen based on silver hybridized mesoporous silica nanoparticles, Anal. Biochem. 434 (2013) 123-127, https://doi. org/10.1016/j.ab.2012.11.012.

[60] C. Li, J. Li, X. Yang, L. Gao, L. Jing, X. Ma, A label-free electrochemical aptasensor for sensitive myoglobin detection in meat, Sensor. Actuator. B Chem. 242 (2017) 1239-1245, https://doi.org/10.1016/j.snb.2016.09.087.

[61] Y. Wang, M. Han, X. Ye, K. Wu, T. Wu, C. Li, Voltammetric myoglobin sensor based on a glassy carbon electrode modified with a composite film consisting of carbon nanotubes and a molecularly imprinted polymerized ionic liquid, Microchim. Acta. 184 (2017) 195-202, https://doi.org/10.1007/s00604-016-2005-2.

[62] G. Zhang, Z. Liu, L. Wang, Y. Guo, Electrochemical aptasensor for myoglobin-specific recognition based on porphyrin functionalized graphene-conjugated gold nanocomposites, Sensors (Switzerland) 16 (2016) 1803, https://doi.org/10.3390/ s16111803.

[63] V.V. Shumyantseva, T.V. Bulko, L.V. Sigolaeva, A.V. Kuzikov, A.I. Archakov, Electrosynthesis and binding properties of molecularly imprinted poly-o-phenylenediamine for selective recognition and direct electrochemical detection of myoglobin, Biosens. Bioelectron. 86 (2016) 330-336, https://doi.org/10.1016/j.bios. 2016.05.101.

[64] N.M. Danesh, M. Ramezani, A.S. Emrani, K. Abnous, S.M. Taghdisi, A novel electrochemical aptasensor based on arch-shape structure of aptamer-complimentary strand conjugate and exonuclease I for sensitive detection of streptomycin, Biosens. Bioelectron. 75 (2016) 123-128, https://doi.org/10.1016/j.bios.2015.08.017. 